REVIEW PAPER

\title{
SENSOR SYSTEMS FOR MAPPING SOIL FERTILITY ATTRIBUTES: CHALLENGES, ADVANCES, AND PERSPECTIVES IN BRAZILIAN TROPICAL SOILS
}

\author{
José Paulo Molin ${ }^{*}$, Tiago Rodrigues Tavares ${ }^{1}$ \\ $1^{1 *}$ Corresponding author. University of São Paulo, "Luiz de Queiroz” College of Agriculture, Department of Biosystems \\ Engineering, Laboratory of Precision Agriculture/ Piracicaba - SP, Brazil. \\ E-mail: jpmolin@usp.br| ORCID ID: https://orcid.org/0000-0001-7250-3780
}

\section{KEYWORDS}

Spatial variability, spectroscopy, on-thego sensing, hybrid laboratory.

\begin{abstract}
Soil fertility attributes have different scales and forms of spatial and temporal variations in agricultural fields. Adequate spatiotemporal characterization of these attributes is fundamental to the successful development of strategies for variable rate application of fertilizers, enabling the classic benefits of precision agriculture (PA). Studies on Brazilian soil have shown that at least 1 sample $\mathrm{ha}^{-1}$ is required for the reliable mapping of key fertility attributes. However, this sampling density is difficult owing to the operational challenges of sample collection and the cost of laboratory analyses. Given this limitation, soil sensors have emerged as a practical and complementary technique for obtaining information on soil attributes, at high spatial density, without the production of chemical residues and at a reduced cost. Scientists worldwide have devoted their attention to the development and application of sensor systems for this purpose. The concept of proximal soil sensing (PSS) was established in 2011 and involves the application of soil sensors directly on the field. PSS techniques involve different disciplines, such as instrumentation, data science, geostatistics, and predictive modeling. The integration of these different disciplines has allowed successful sensor application for the spatial diagnosis of soil fertility attributes. The present work aimed to present a bibliographic review of the concepts involved and main techniques used in soil sensing to predict fertility attributes. We sought to present a broad view of the challenges, advances, and perspectives of sensor application in Brazilian tropical soils in the context of PA.
\end{abstract}

\section{INTRODUCTION}

Linked to the technological advances of the last decades and considered by some authors as one of the top 10 revolutions in agriculture in the last 50 years (Crookston, 2006; Mulla, 2013), precision agriculture (PA) advocates the adequate treatment of spatial and temporal variability of crops (Molin et al., 2015). The objective of PA is to promote the spatially optimized management of agricultural inputs, which increases productivity and facilitates the rational use of production resources. These features of PA make it a promising tool to overcome the global challenges of agriculture in the $21^{\text {st }}$ century (Gebbers \& Adamchuk, 2010). These challenges include achieving food and energy security for more than 9 billion people in the coming decades (Godfray et al., 2010) and aligning agricultural production and environmental conservation practices (Foley et al., 2011).

Since its conception in the mid-1980s, PA has been closely associated with the management of the spatial variability of soil fertility. Prior to the development of variable rate technologies and satellite positioning systems, soil scientists had already undertaken spatial sampling and

${ }^{1}$ University of São Paulo, "Luiz de Queiroz" College of Agriculture, Department of Biosystems Engineering, Laboratory of Precision Agriculture/ Piracicaba - SP, Brazil.

Area Editor: Fabio Henrique Rojo Baio

Received in: 07-27-2019

Accepted in: 07-29-2019 
got intrigued by the high spatial variability of fertility in agricultural fields (Mulla \& Khosla, 2016). After evaluating more than 70 agricultural fields in the state of Washington (USA) using intensive soil sampling, Dow et al. (1973a, b) concluded that fertilization recommendations based on the fertility average may be erroneous. These authors suggested the use of sampling intensification for more accurate fertilizer prescription. During the following decade, the development of variable rate systems helped to evaluate the localized management of soil fertility. Results of the pioneering works in this evaluation were positive and encouraging, showing increased productivity (Mulla \& Hammond, 1988; Hammond, 1993) and improved nutrient use efficiency (Khosla \& Alley, 1999).

The traditional management of fertilizers and limestone, without considering the spatial variability, involves the inefficient application of these inputs with an excess or deficit at specific sites. In excessive applications, the nutrients that are not used by plants and retained by the soil are lost to the environment through leaching, runoff, and emissions. The excess compounds increase the contamination levels in the soil and water, representing a hidden cost for society (Hyytiäinen et al., 2011). Regarding input deficits, these impose negative influences on the development of crops and, consequently, on their production. Thus, adjusted and spatially accurate nutrient applications can reduce agronomic, economic, and environmental losses (Nawar et al., 2017).

Brazil is the fourth-largest fertilizer consumer in the world (FAO, 2017). This has been attributed to the predominance of soil with an acid character and low fertility, as well as to the practice of PA in the country, which involves the management of fertilization and soil acidity correction based on the mapping of soil attributes at the field level. PA is associated with significant service delivery markets in the country and approximately $15.3 \%$ of Brazilian grain producers use this approach, with an estimated 9 million ha of mapped soils (Molin, 2017).

For the successful implementation of the variable rate application of soil inputs, reliable procedures and technologies are required for the diagnosis of spatial variability of the different soil fertility attributes. The methodological procedure predominantly used today in Brazil involves the collection of samples in a regular grid, or occasionally using other arrangements, with georeferenced sampling points. These samples are sent to laboratories for analysis and, subsequently, maps are created using interpolation methods. However, the sampling density is limited by the costs of the laboratory tests and the operational difficulties regarding sampling logistics (McBratney et al., 2003; Demattê et al., 2015a). Previous studies on Brazilian soils have demonstrated that the density traditionally used today $\left(<0.5\right.$ samples $\left.\mathrm{ha}^{-1}\right)$ is not adequate for the reliable characterization of the spatial distribution of most fertility attributes (Nanni et al., 2011; Cherubin et al., 2015). This corroborates with different international studies conducted over the past few decades (Webster \& McBratney, 1987; McBratney \& Pringle, 1999; Viscarra Rossel et al., 2011).
Despite the evolution of PA approaches and technologies, the diagnosis of spatial variability of soil fertility attributes is still a challenge worldwide (Viscarra Rossel \& Bouma, 2016). The major challenge is how to increase the density of data on soil fertility attributes without sending more samples for laboratory analysis. Soil sensing is a promising solution to this problem. Recently, the application of different sensing techniques, to obtain digital data related to soil attributes, has received great attention from scientists involved in PA (Adamchuk et al., 2004) and pedometry (Brevik et al., 2016). The concept of proximal soil sensing (PSS) was established by Viscarra Rossel et al. (2011) and refers to the use of sensors that are compatible with on-field operations that act in contact or close to the soil surface (around $2 \mathrm{~m}$ ).

Sensors with analytical methods that are compatible with the direct analysis of solids, that is, those that avoid the classic procedure of wet chemistry, allow for operations with minimum or no sample preparation (Krug \& Rocha, 2016). Most of these techniques have been employed for decades as laboratory analytical methods. The innovative appeal is related to recent advances in nano and microengineering, which have enabled the construction of equipment with reduced weight and size, greater robustness, and at affordable prices, making them more compatible with in situ works (Dhawale et al., 2015). Another challenge is to take advantage of the current knowledge regarding the use of each sensor and adapt it to use these sensors directly in the field as a tool for the management of fertility of tropical soils. One of the main tasks is to minimize the loss of data quality when different techniques for sample collection are used under different field conditions (Galuszka et al., 2015). The loss of analytical accuracy would be compensated for by the massive increase in information (Molin et al., 2015) and by the use of spatial and statistical filtering methods already established for other PA approaches (Menegatti \& Molin, 2004; Leroux et al., 2018), which allow for the removal of coarse errors.

Recently, new technologies to characterize spatial variability in soil, e.g. gamma-rays (Castrignanò et al., 2012), visible and near-infrared spectroscopy (vis-NIR) (Mouazen \& Kuang, 2016), and X-ray fluorescence (XRF) (Nawar et al., 2019) have been gaining attention from scientists. These new technologies, as well as the development of statistical techniques, multivariate geostatistics, and artificial intelligence, have greatly increased the ability to collect, analyze, and predict spatial information related to soils (Brevik et al., 2016). Linking all this new information to decision making for localized management still has its challenges. Understanding the potential and limitation of each technology, as well as maintaining the focus on the central objective of developing more efficient agricultural production systems, should be the central guidelines for the development of practical approaches to using soil sensing. The present study aimed to present a systematic review of the concepts involved and techniques used in soil sensing for predicting fertility attributes. We sought to critically discuss the challenges and advances in the use of sensing techniques in Brazilian tropical soils and to present several application perspectives in the context of PA. 


\section{Diagnosis of spatiotemporal variability of soil fertility}

For the detailed management of soil fertility of agricultural fields, physical and chemical properties, such as the clay, sand, and organic matter (OM) content; cation exchange capacity (CEC); $\mathrm{pH}$; and available nutrients, should be known at proper spatial resolution. The spatiotemporal variability of these attributes is dynamic, occurring with different amplitudes of variation and spatial patterns. These variations occur according to the classical factors of soil formation (McBratney et al., 2003) and owing to minor alterations caused by a combination of local factors such as relief and management (Viscarra Rossel \& Lobsey, 2016). Figure 1 presents images of several factors that are commonly associated with the spatiotemporal variability of soil fertility attributes, elucidating amplitudes and patterns of variation in soil attributes.

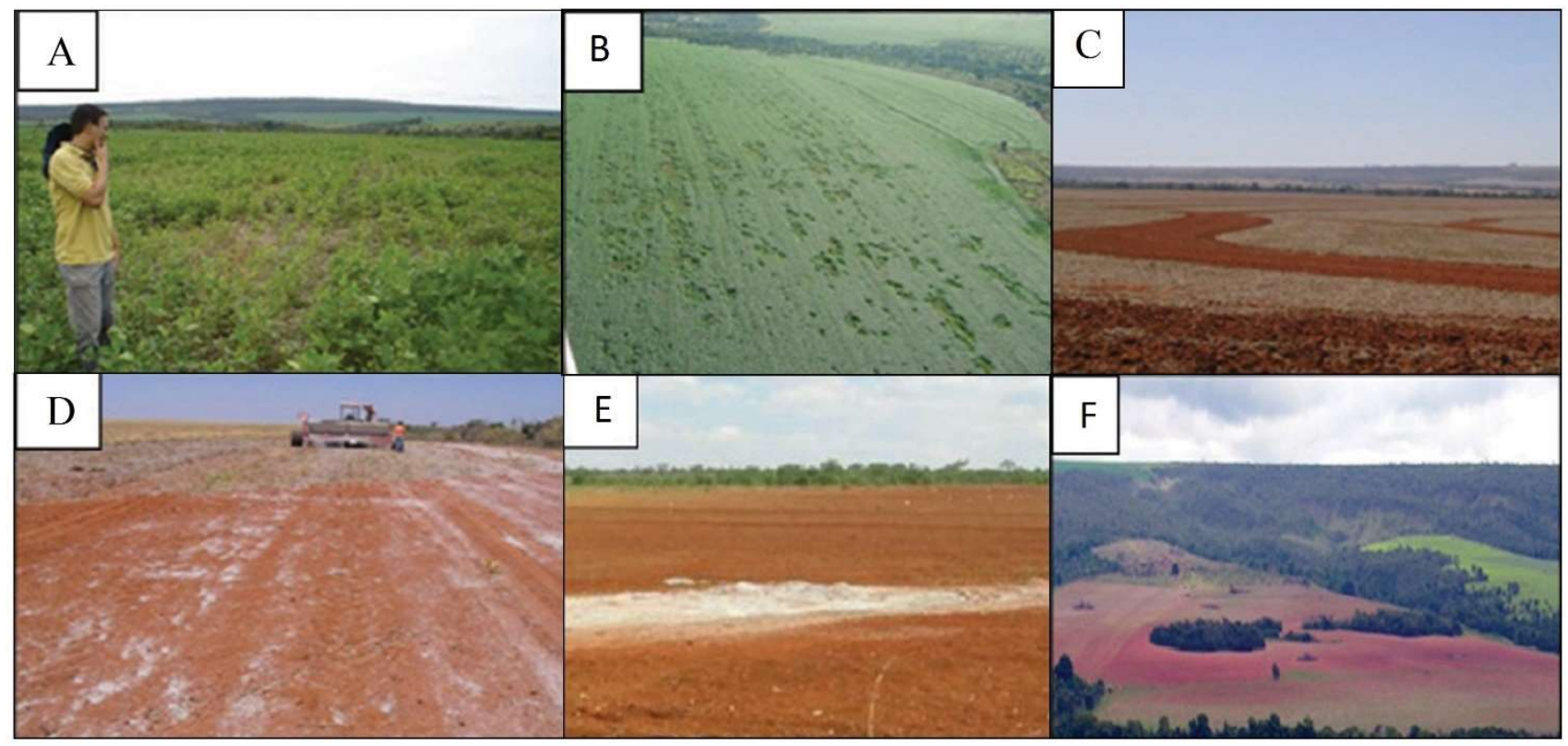

FIGURE 1. Factors associated with the spatiotemporal variability of soil fertility attributes (adapted from Resende \& Coelho, 2017). (A and B) Damage to growing crops by pests, diseases, or weather promotes heterogeneous nutrient export patterns in fields; (C) Exposure of the subsoil in contour banks; (D) Non-uniform application of fertilizers and lime; (E) Limestone deposits; and (F) Abrupt natural changes in soil formation factors.

Understanding the potential spatial dependence ranges and patterns of the variables to be mapped is fundamental for the establishment of the sampling density. Sampling must represent a whole statistical population. Therefore, in agricultural fields, each "spot" and the transitions between them must be characterized by sampling points to discriminate not only the variation in soil attributes but also its spatial pattern (Molin et al., 2015). Soil fertility characterization was the objective of the first studies related to PA. Research by David Mulla at Washington State University evaluated the diagnosis of fertility attributes utilizing sampling grids with different spacings. The author suggested that the sample grids should be between 30 and $60 \mathrm{~m}$ apart for an accurate representation of fertility attributes (reported by Veseth, 1986). Wollenhaupt et al. (1994) also compared the sample density for fertility mapping and reported that the spacing between samples that best represented the fertility was $32 \mathrm{~m}$ and maps produced with samples spaced at $70 \mathrm{~m}$ had significantly reduced accuracy.

Several local studies have characterized the spatial dependence of physical and chemical attributes of Brazilian soils via geostatistical analyses to calculate the best sample density (Nanni et al., 2011; Montanari et al., 2012; Cherubin et al., 2014a, b; Cherubin et al., 2015). The geostatistical results vary according to the local characteristics; however, sample grids greater than $100 \times 100 \mathrm{~m}\left(1\right.$ sample ha- $\left.^{-1}\right)$ are not efficient for characterizing the variability of most soil fertility attributes. An example of available $\mathrm{P}$ mapping using different sampling densities is shown in Figure 2. Generally, factors related to the soil class and its formation (e.g., texture) require a lower sampling density. However, for $\mathrm{pH}$ and available $\mathrm{P}, \mathrm{K}, \mathrm{Ca}, \mathrm{Mg}$, and other chemical attributes, a higher sample density is required to characterize the variability (Wetterlind et al., 2010). 


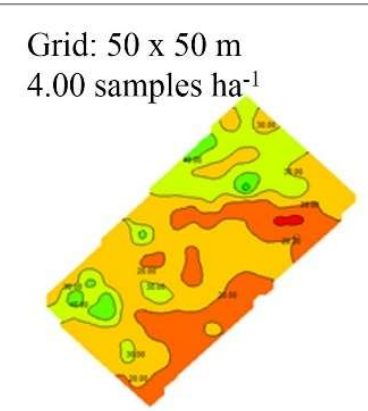

Grid: $150 \times 150 \mathrm{~m}$ 0.44 sample ha-1

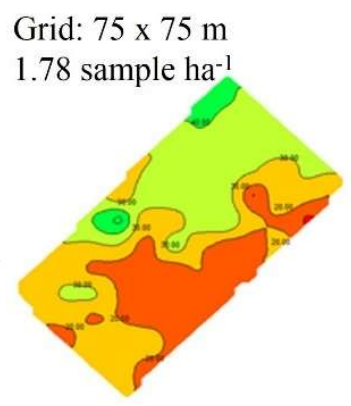

Grid: $175 \times 175 \mathrm{~m}$ 0.33 sample ha-1

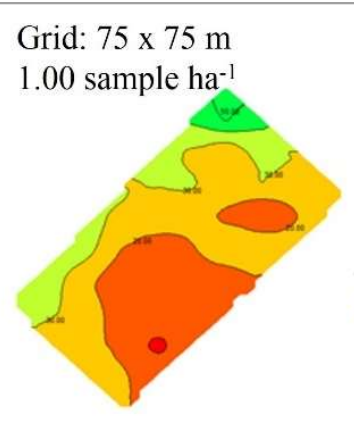

Grid: 125 x $125 \mathrm{~m}$

0.64 sample ha-1

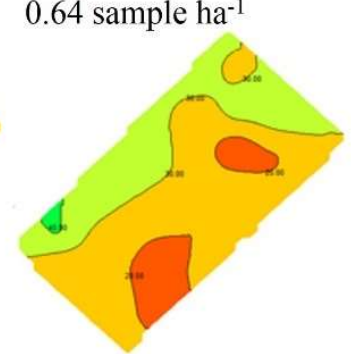

Grid: $200 \times 200 \mathrm{~m}$

0.25 sample ha-1 $^{-1}$

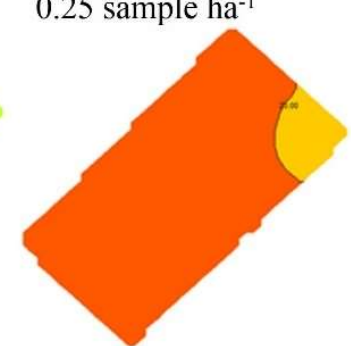

FIGURE 2. Spatial distribution of available P using different sample densities in a 42-ha field (adapted from Cherubin et al., 2015).

Schirrmann and Domsch (2011) compared the spatial characterization of $\mathrm{pH}$ and available nutrients $(\mathrm{P}, \mathrm{K}$, and $\mathrm{Mg}$ ) between sampling using a grid of $50 \mathrm{~m}$ (4 samples $\left.\mathrm{ha}^{-1}\right)$ with that collecting samples every $25 \mathrm{~m}$ (16 samples $\mathrm{ha}^{-1}$ ), with the latter chosen to simulate the sampling achieved with the on-the-go system proposed by Adamchuk et al. (2006). In general, the sampling with the higher resolution improved the results of the semivariograms, allowing clear identification of spatial structures of available $\mathrm{pH}, \mathrm{P}$, and $\mathrm{Mg}$. In addition, intensive sampling allowed interpolations using kriging with higher predictive accuracy. However, despite better results with highresolution sampling for most of the evaluated attributes, Schirrmann and Domsch (2011) did not achieve good spatial models for the available K. According to the authors, the microscale variation of available $\mathrm{K}$, with a spatial dependence range less than $25 \mathrm{~m}$, limited the characterization of this nutrient.
A short spatial dependence, marked by a short-range semivariogram, requires high spatial density sampling to generate reliable spatial diagnostics. A review conducted by Viscarra Rossel and Lobsey (2016) showed that the spatial variability range of physical and chemical attributes in soils ( 0 to $20 \mathrm{~cm}$ of depth) fluctuated between $<10$ and $100 \mathrm{~m}$ (Table 1). Furthermore, it is not unusual for agricultural fields to have variations in microscale nutrients, as reported by Schirrmann and Domsch, (2011). For a proper diagnosis of a specific soil attribute using grid sampling, researchers recommend that the minimum spacing between samples should be equal to or less than half of the spatial dependence range (Molin et al., 2015), i.e., a sampling density that is greater than 1 sample $\mathrm{ha}^{-1}$. However, this is a density that is incompatible with field sampling and the costs of laboratory tests (Demattê et al., 2015a; Viscarra Rossel \& Bouma, 2016).

TABLE 1. Spatial and temporal variability of soil attributes (adapted from Viscarra Rossel \& Lobsey, 2016).

\begin{tabular}{ccc}
\hline Soil attribute & Spatial variability (amplitude) & Temporal variability \\
\hline Texture & Moderate-high (between 20 and $98 \mathrm{~m}$ ) & Low \\
Organic carbon & High (between 22 and $78 \mathrm{~m}$ ) & Moderate (between 5 and 10 years) \\
CEC & Moderate-high & Moderate \\
pH & Moderate-high (between 30 and $100 \mathrm{~m}$ ) & Moderate-high (between season) \\
Available P & High (between $<10$ and $31 \mathrm{~m}$ ) & High (within and between season) \\
Available K & High (between 18 and $68 \mathrm{~m})$ & Moderate-high (within and between season) \\
\hline
\end{tabular}

\section{Challenges and opportunities of using soil sensors}

Owing to the challenges associated with the spatiotemporal characterization of soil attributes, sensing technologies enable the monitoring of agricultural soils at a low cost, even as with a high sampling resolution and satisfactory accuracy. The development of (i) sensor systems compatible with on-line measurements and/or (ii) portable sensor systems well-matched with easy-to-use analytical procedures [e.g., the concept of a mobile laboratory (Pandey et al., 2017)] are two alternatives that can increase the quantity of soil information (Figure 3). The first alternative is related to the use of PSS techniques and it would minimize the effort related to sample collection, cost of traditional laboratory analyses, and use of reagents during the analyses. The second alternative is related to practical analytical methods that are executable by the user. However, it would only provide a partial solution, reducing laboratory costs and the use of reagents, but it still requires the execution of geo-referenced sample collection and analysis. 


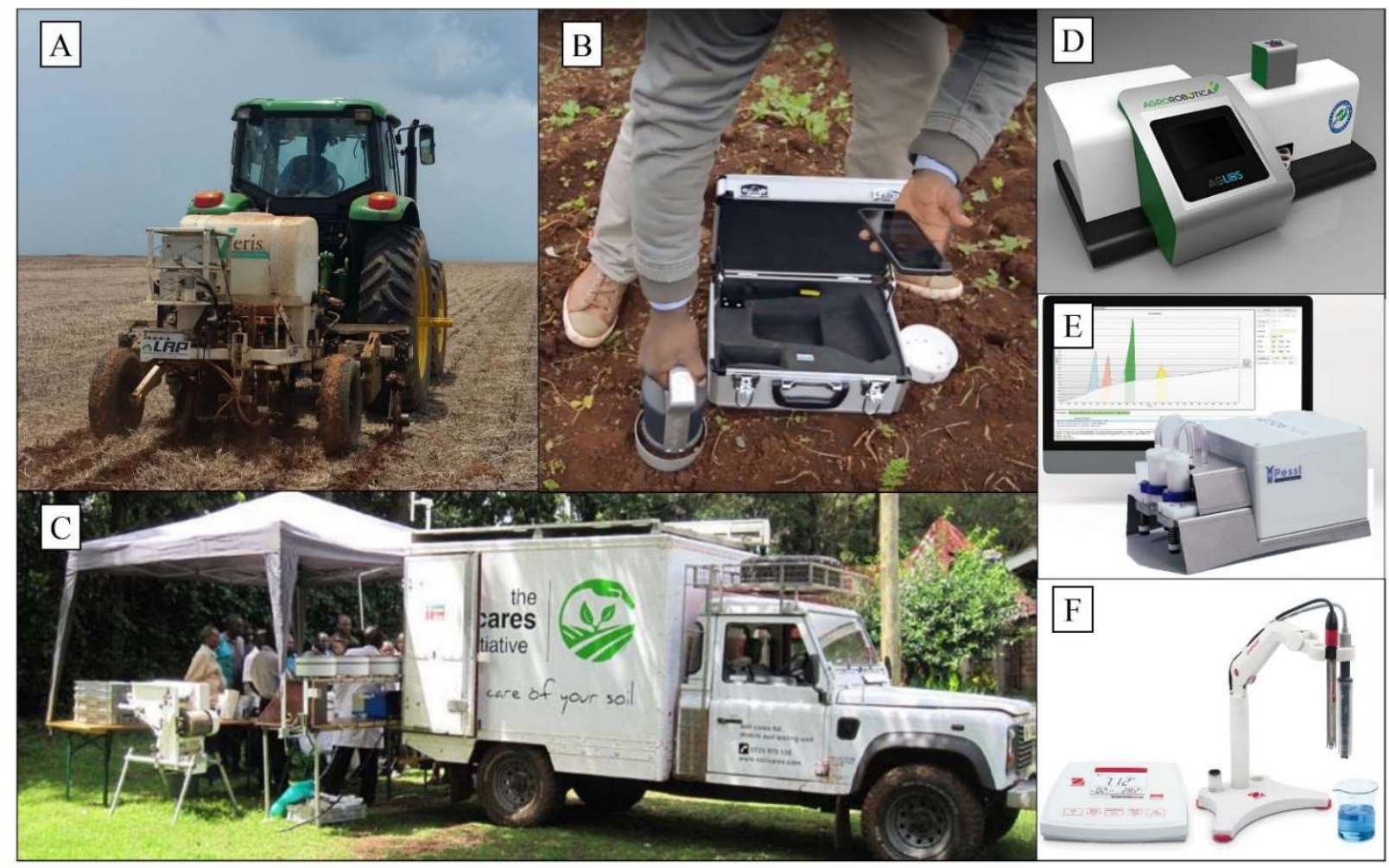

FIGURE 3. Alternative soil sensing approaches for increasing the quantity of soil information. (A) Sensors embedded in mobile platforms; (B) Sensors placed directly in the field in a stationary operation (Agrocares, Wageningen, Holland; https://www.agrocares.com/en); (C) Mobile laboratories for conducting simple sample preparation procedures and practical analysis (Agrocares, Wageningen, Holland; https://www.agrocares.com); and some sensor systems compatible with mobile laboratories: (D) laser-induced breakdown spectroscopy system developed by Agrorobótica company (São Carlos, SP, Brazil; https://agrorobotica.com.br) in partnership with Embrapa Agricultural Instrumentation (São Carlos, SP, Brazil), (E) Capillary electrophoresis system developed by Pessl (Weiz, Austria; https://metos.at/imetos-mobilab); and (F) Electrochemical sensor system developed by Ohaus ${ }^{\mathrm{TM}}$ (Parsippany, NJ, USA; https://br.ohaus.com).

The idea of adapting different sensor systems to user-friendly approaches that are compatible with mobile laboratories comes very close to the concept of hybrid laboratory, recently discussed by Demattê et al. (2019). According to the authors, in a hybrid laboratory, some of the samples are analyzed by traditional methods and used to calibrate the predictive models, while the majority of the samples are analyzed using sensing technologies, applying the generated predictive models. Hybrid laboratories in mobile environments are an interesting alternative to increase the efficiency of laboratory tests with low environmental impact. This should boost Brazilian research in the coming years to seek the best set of sensors compatible with direct analysis of Brazilian tropical soils, as well as the best strategy for the calibration of predictive models at local and regional scales.

In PA, on-field sensor applications are a classic sensing alternative for increasing the quantity of soil information and has been proposed since 1990 for the localized management of agricultural fields (Sudduth \& Hummel, 1991; Hummel et al., 1996). Applications of soil sensors that operate proximally to the target and are compatible with direct field operations are called PSS techniques (Viscarra Rossel et al., 2011). Sensors compatible with PSS have been systematically described by Viscarra Rossel et al. (2011) regarding the way they take their measurements [invasive (in situ or ex situ) or non-invasive], source of energy (active or passive), operation (stationary or mobile), and the inference used in the measurement of the target soil property (direct or indirect). Thus, all the classic on-the-go sensors that acquire data in a kinematic way (Adamchuk et al. 2004) fit the concept of PSS. Soil sensors that are compatible with on-the-go acquisition can be embedded in agricultural equipment, thus allowing the acquisition of data during field operations (Steinberger et al., 2009). Recently, companies have introduced in-market sensor systems that are adaptable in seeders and equipment for soil preparation, e.g., iScan (Veris Technologies, Salina, KS, USA) and SmartFirmer (Precision Planting, Tremont, IL, USA). This strategy permits the acquisition of soil data during routine operations, as well as allowing real-time adjustments of the plant population and depth for instrumented seeders. These applications, although promising, require local assessments of sensor performance and agronomic algorithms to adjust the recommendations.

In the context of PA, there is a constant search for sensor systems that are compatible with on-the-go measurement, thus enabling real-time interventions (Molin et al., 2015). In this case, the data are processed at the same time as they are collected; that is, data are transformed into information using agronomic prescriptions (e.g., Kodaira \& Shibusawa, 2013). Although these systems tend to be practical and easy to implement in the field, their development requires specific analysis protocols and agronomic models, forming a complex system of intelligence for the transformation of data into agronomic intervention (Weltzien, 2016). In the context of soil sensing, the interpretation of the relationship between sensor output 
and soil attributes is the main challenge for the development of sensor systems for real-time intervention.

The assessment of the accuracy of sensing techniques is undertaken by comparing the prediction given by sensors with that provided by traditional laboratory methods (Kuang et al., 2012). To build robust predictive models, the calibration strategy is important, in which the responses of the sensors will be related to the reference values obtained in the laboratory (Kuang \& Mouazen, 2011). Although this is the globally used approach for evaluating new sensing technologies, the use of laboratory analyses as a reference for creating calibration models has some drawbacks, as discussed by Viscarra Rossel and Bouma (2016). These disadvantages include (i) propensity of different sources of error during sampling, sample preparations, and analysis; and (ii) the fact that none of the different extracting solutions used for nutrient analysis produces a value that indeed represents the available content for plants because the availability of nutrients in the soil is dynamic and depends on multiple factors related to environmental conditions and soil-plant interactions.

It is relatively common to observe discrepant results from different laboratories for the same soil sample analyzed under the same conditions. Such observations have been reported by studies conducted in Brazil (Eitelwein, 2017; Demattê et al., 2019) and overseas (Viscarra Rossel \& Bouma, 2016). The calibration of sensor systems with doubtful laboratory results interferes with the performance evaluation. This should be considered by researchers, who should be aware of the methodological procedures and quality control of the laboratory they are utilizing. Sending samples to different laboratories could also be a strategy to verify the analysis results.

The use of PSS associated with information at high spatial resolution of yield (yield maps) and in-season development of crops (e.g., vegetation indices obtained by canopy sensors or remote sensing) has enormous potential for improving on-farm trials methodologies (Viscarra Rossel \& Bouma, 2016), which can improve the recommendation of fertilizer application rates. Such approaches would allow the creation of local databases, based on empirical estimations, and the development of fertilizer strategies specific for each field condition, thus avoiding the use of highly generalized data, such as regional fertilizer guides.

\section{Sensor systems for soil sensing}

PSS is defined as the use of sensors directly in the field, with the detectors in contact or close to the soil surface (around $2 \mathrm{~m}$ ) (Viscarra Rossel et al., 2011). Although this concept excludes remote sensing applications and measurements with sensors performed in the laboratory using benchtop equipment, such approaches may be complementary to PSS because the development of many sensors starts with laboratory tests and most soil sensors use calibrations derived from laboratory measurements.

Some soil sensing technologies addressed in this present study are not compatible with the PSS concept because their design concepts still require some sample preparation to ensure the sensor analytical capabilities (e.g., laser-induced breakdown spectroscopy; LIBS), which is a limitation for field applications. However, these sensing technologies can be promising for soil analysis in the context of PA because they are compatible with easy-to-use analytical procedures. Moreover, the development of faster and more efficient methods of sample preparation-a research area of Analytical Chemistry that has been greatly intensified in recent years (Krug \& Rocha, 2016) - should allow the automation of this process in embedded equipment. This would enable the application of such technologies in the field, even as the performance improvement of some sensor systems that are already compatible with PSS. The study by Sethuramasamyraja et al. (2008) is a classic example of an automated procedure for the collection and preparation of soil samples. The authors adapted a commercial instrument $(\mathrm{pH}$ Manager, Veris Technologies, KS, USA; on-the-go system of electrochemical sensors) for the preparation of an aqueous solution with the soil, before using ion-selective electrodes.

Soil sensors can be classified based on their design concept as follows: (i) optical/radiometric, (ii) electrical/electromagnetic, (iii) electrochemical, and (iv) mechanical (Adamchuk et al., 2004; Kuang et al., 2012). These allow the measurement of the soil capacity to (i) absorb, reflect, and/or emit electromagnetic energy; (ii) accumulate or conduct electrical charge; (iii) release ions; and (iv) resist mechanical distortions (Viscarra Rossel \& Lobsey, 2016), respectively. Figure 4 shows some promising technologies for the direct analysis of soils.

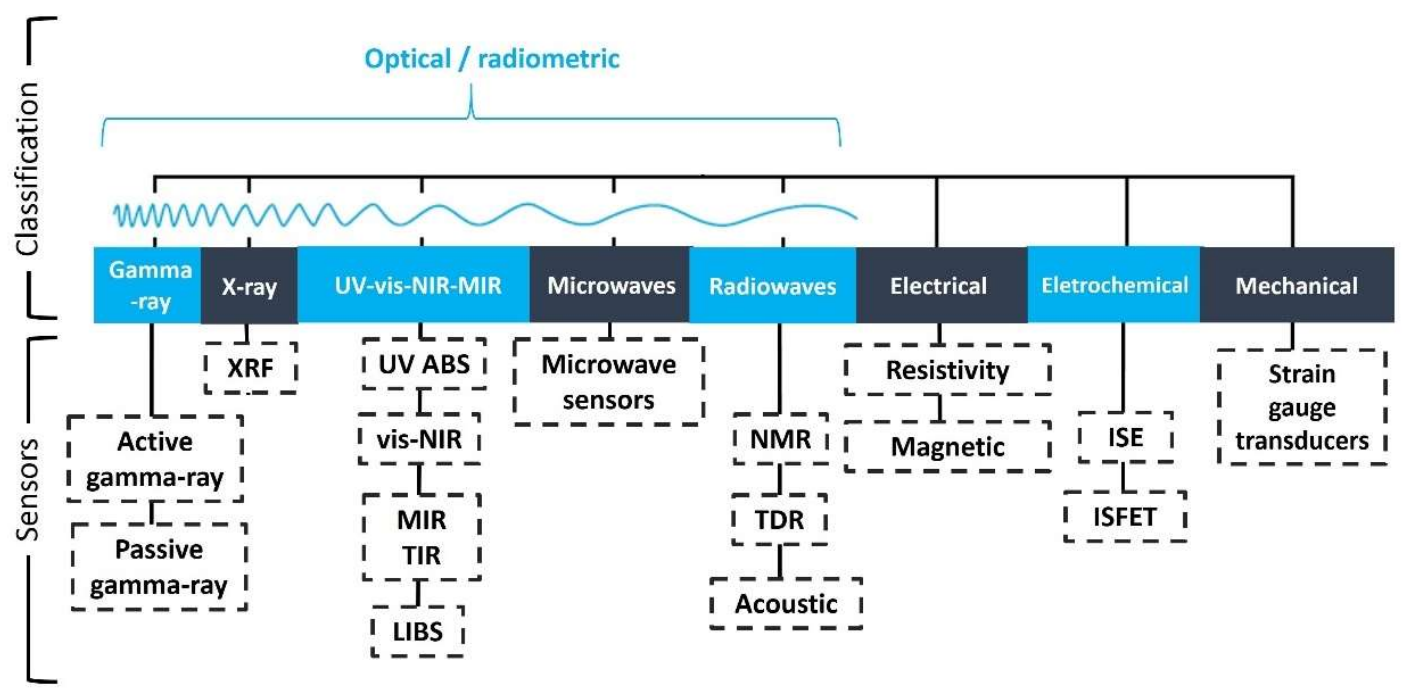

FIGURE 4. Some available technologies for the direct analysis of soils (adapted from Viscarra Rossel \& Lobsey, 2016). 
Studies have been conducted worldwide to develop sensors and techniques to map soil attributes (Adamchuk et al., 2004; Kodaira \& Shibusawa, 2013; Nawar et al., 2019). Innovative applications have been proposed for exploring the local relationship between soil attributes and the output of different sensor systems, such as the use of vis-NIR spectroscopy for localized P management (Mouazen \& Kuang, 2016), the use of apparent electrical conductivity (ECa) for localized limestone application (Sanches et al., 2018), and the use of sensor systems and multivariate statistical techniques to synthesize the main variables of soil fertility in a fertility index, providing an important layer of information for the generation of management zones (MZ) (Viscarra Rossel et al., 2010; Whetton et al., 2018). These studies will be discussed in the following sections, which also analyze the working principles and recent developments in different sensing techniques, emphasizing their applications in Brazilian tropical soils.

\section{Electrical/electromagnetic sensors}

Electrical or electromagnetic sensors are already popular in PA and characterize on-the-go data acquisition and high spatial density. The continuous and non-invasive measurement of the ECa of soil was presented for the first time at the end of the 1970s by De Jong et al. (1979). These authors used an electromagnetic induction sensor EM-31 (Geonics Ltd., Mississauga, ON, Canada) to evaluate the changes in soil salinity at different depths along a transect.

Electrical and electromagnetic sensors evaluate the capacity of the soil to accumulate or conduct an electrical charge by measuring its ECa, which is traditionally evaluated in agricultural soils by electromagnetic induction (e.g., EM-38, Geonics Ltd., Mississauga, ON, Canada) or electrical resistivity measured by galvanic contact (e.g., Veris EC, Veris Technologies, KS, USA). ECa sensors that use electromagnetic induction usually contain a transmitter and a receiver, which do not come into direct contact with the soil. This type of ECa sensor uses a variable magnetic field, with relatively low frequency $(\mathrm{kHz})$ to induce electrical currents in the soil, ensuring that its amplitude is linearly related to soil conductivity. The magnitude of this conductivity is determined by the generated magnetic field (Viscarra Rossel et al., 2011). In contrast, ECa sensors that measure the electrical resistivity must be in galvanic contact with the soil. These sensors usually use two pairs of electrodes: one to inject current and another to measure the resulting potential difference. The potential difference reflects the electrical resistivity of the soil, which is the inverse of the conductivity (Adamchuk et al., 2004). In both systems, by altering the strength of the magnetic field or the distance between the electrodes, it is possible to evaluate $\mathrm{ECa}$ at different depths, starting on the soil surface (Adamchuk \& Viscarra Rossel, 2010).

The spatial density of data obtained by both forms of ECa measurements is determined by the speed of operation, frequency of data acquisition (usually $1 \mathrm{~Hz}$ ), and distance between the parallel lines that the equipment is pulled along in the field. Thus, considering a constant velocity of $4 \mathrm{~ms}^{-1}$, distances of 10,20, and $30 \mathrm{~m}$ allow the acquisition of 250,125 , and 83 points ha ${ }^{-1}$, respectively. Although this density is higher than that used in soil sampling (usually $<1$ sample ha ${ }^{-1}$ ), this form of data acquisition should also be considered as a sampling procedure. Thus, the velocity and distance between lines can be optimized by aligning the density of points to be collected with the spatial variability range of the target attribute. Further details on the optimization and planning of data acquisition with soil sensors, as well as a cost evaluation based on the field operation strategy, have been reviewed by Gruijter et al. (2010).

The alteration of soil physical and chemical properties affects its ability to conduct an electrical current and, therefore, can influence the parameters measured by the ECa sensor. The interpretation of soil ECa is somewhat dynamic because it is influenced by a combination of factors. However, it is intrinsically related to soil moisture (Corwin \& Lesch, 2005; Fortes et al., 2015). In addition, it can be used as an indicator of salinity, texture, moisture, density, and CEC (Doolittle et al., 1994; Corwin \& Lesch, 2005; Sudduth et al., 2005).

Most studies have reported satisfactory relationships between ECa and soil texture and moisture in Brazilian soils (Machado et al., 2006; Molin \& Rabello, 2011; Molin \& Faulin, 2013). Molin and Rabello (2011), using the commercial equipment Veris EC, observed a coefficient of determination $\left(\mathrm{R}^{2}\right)$ higher than 0.74 for the clay content. The authors also reported that the soil ECa is a function of the interaction between texture and water content and, because of the oscillations of water content in soils, different ECa values can be obtained if it fluctuates. This same phenomenon can also occur with the oscillation of any other parameters that relate indirectly to $\mathrm{ECa}$ (e.g., density) (Adamchuk \& Viscarra Rossel, 2010). In these cases, weak correlations between ECa and texture can be observed, as found by Molin et al. (2005). The sensor sensitivity for the evaluation of soil texture is related to the soil moisture present. Higher contents of water allow for better correlations with texture and, on the other hand, evaluations with dry soil should be avoided owing to the low sensitivity of this sensor to textural variations (Molin \& Faulin, 2013). Therefore, the best conditions for texture mapping using ECa occur when the soil moisture is slightly below the field capacity. Excessive water content should also be avoided because the results will no longer reflect textural parameters, with the electrical conductivity of the soil solution predominating.

In some cases, the literature has shown satisfactory relationships between ECa and soil attributes such as CEC and available nutrients (Officer et al., 2004). In Brazilian soils, Molin and Castro (2008) obtained good predictions $\left(\mathrm{R}^{2}>0.70\right)$ of available $\mathrm{K}$ and $\mathrm{Ca}, \mathrm{CEC}$, base saturation (V $\%), \mathrm{OM}$, and clay. When observed, these relationships can be explored for a more assertive mapping of such attributes. Sanches et al. (2018) used ECa information in a 50-ha field to perform targeted soil sampling (one sample every 2.5 ha or 0.4 sample ha ${ }^{-1}$ ) and afterward interpolated soil fertility attributes using kriging with external drift (KDE). In the same area, the authors performed a dense sampling with 4 samples $\mathrm{ha}^{-1}$ to compare with the previous approach. After interpolation, the performance of both mapping strategies was evaluated using 50 new sampling points. The authors obtained better mapping for almost all soil attributes using ECa-targeted soil sampling combined with KDE interpolation, concluding that this approach was promising to increase the accuracy of soil fertility maps using a reduced number of collected samples.

Another important feature of soil ECa is its temporal stability (Molin \& Faulin, 2013; Serrano et al., 2017), which is also influenced by its relationship with soil texture. The 
spatial patterns of ECa generally remain constant over time, regardless of its magnitude. Thus, multiple ECa measurements on the same field might allow inferences on other soil properties affecting ECa beyond texture, such as moisture (Brevik et al., 2006; Hossain et al., 2010), salinity (Zare et al., 2015), and density (Hoefer et al., 2010).

The spatial patterns of ECa in agricultural fields are commonly used as an important layer of information for defining MZ (Molin \& Castro, 2008; Nawar et al., 2017). $\mathrm{MZ}$ are areas of the field that present combinations of yieldlimiting factors that are relatively homogeneous and that are stable over time (Vrindts et al., 2005). Thus, the association of ECa spatial information - as well as the output of other sensor systems, such as active canopy sensors, remote sensing data, and other soil sensing techniques - with high resolution and multitemporal yield data allow more robust estimates of $\mathrm{MZ}$ for the consideration of factors that vary year-to-year, such as weather conditions, pests, and diseases (Brock et al., 2005). In Brazil, Sanches et al. (2019) demonstrated the application of ECa for the classification of production environments for sugarcane cultivation. The concept of the production environment is based on soilclimate interactions to define areas of similar productive potential (Prado, 2005). It is a well-disseminated technique and is used by sugarcane growers in the South-Central region of Brazil. This concept approximates to the idea of MZ, but in lower spatial resolution. Different practices of sugarcane crop management (e.g., choice of varieties, fertilization, planting time, and harvest) are determined based on the production environment (Sanches et al., 2019).

ECa equipment generally allows for data collection at multiple soil depths, enabling applications for the spatial estimation of soil attributes at different depths and the 3D modeling of these attributes (Monteiro et al., 2010). The indepth measurement of ECa allows for the monitoring of horizons with a textural gradient (Sudduth et al., 2001). However, one disadvantage of 3D modeling using on-thego measurement of $\mathrm{ECa}$ is the collinearity of data from different depths, as the deeper sensing (e.g., from 0 to 90 $\mathrm{cm}$ ) includes information about the shallowest sensing (e.g., from 0 to $30 \mathrm{~cm}$ ) (Sudduth et al., 2013).

For vertical ECa data acquisition without collinearity, ECa sensors have been placed in cone penetrometers (Pan et al., 2014). The configuration of the sensor electrodes is equatorial (dipole-dipole type) (Pan et al., 2014), which allows for point measurements of ECa, i.e., without collinearity between data from different depths. Sudduth et al. (2013) measured ECa vertically using dipoledipole electrodes coupled to a penetrometer and obtained accurate predictions of the topsoil depth $\left(\mathrm{R}^{2}>0.9\right)$, as well as a more realistic characterization of soil profiles. Combining this information with on-the-go mapping of ECa improved the 3D model of this parameter; however, the vertical measurement hindered the densification of the data.

Although its interpretation is dynamic, systems that measure the soil ECa are excellent tools for the spatial variability characterization of agricultural soils. The acquisition of ECa data is still predominantly performed in an exclusive operation; however, the incorporation of these sensors into farming equipment (e.g., iScan, Veris Technologies, KS, USA) is a trend that should increase the availability of these data for agricultural managers. For contact ECa sensors, the challenge is less complex than that of induction sensors, which require the physical removal of metals. Recently, an induction sensor system that claims to overcome this limitation has emerged in the market (Topsoil Mapper, Geoprospectors, Austria). Such solutions can reduce operational limitations, especially those associated with the lack of soil moisture availability at times when there are no crops in the field. Despite being a relatively well-known technique among PA users, there are few studies in Brazilian soils focusing on practical approaches using ECa for localized soil management.

\section{vis-NIR-MIR spectroscopy}

Diffuse reflectance spectroscopy (DRS) is a soil sensing technique characterized by its practicality, low operating cost, non-destructive nature, multiinformational spectra, and compatibility with little or no sample preparation (Stenberg et al., 2010). Another important feature of DRS is the possibility of registering spectral data on points or images using different platforms, e.g., using sensors directly on the field, using benchtop sensors in the laboratory with sampled material, or using remote sensing platforms with multi or hyperspectral cameras. DRS involves remote, proximal (on-field), or laboratory measurements and is a promising technique for digital soil mapping (McBratney et al., 2003) and PA (Adamchuk et al., 2004).

DRS has been used in Soil Science since the beginning of 1950 (Brooks, 1952). However, only in the last three decades has it gained importance with the development of more practical applications, which is mainly associated with the establishment of chemometrics and multivariate statistical techniques in Analytical Chemistry. (Viscarra Rossel et al., 2011). Several scientific studies have successfully estimated soil physical and chemical properties using DRS in the spectral regions of the visible (vis; 400-700 $\mathrm{nm}$ ), near-infrared (NIR; 700-2500 nm), and medium infrared (MIR; 2500-25000 nm) ranges (Ben-Dor \& Banin, 1995; Viscarra Rossel et al., 2006). Moreover, DRS has been successfully applied directly in the field using sensors embedded in mobile platforms (Shibusawa et al., 1999; Mouazen et al., 2007; Christy, 2008) and portable sensors (Dhawale et al., 2015).

Diffuse reflectance is the percentage of the incident radiation that is diffusely reflected by the soil at different wavelengths. The reflectance response of the soil, after its interaction with the different incident wavelengths, constitutes its spectral behavior, which is represented by a spectrum. The spectra produced are the result of interactions between atoms and molecules of the soil and the incident radiation, which penetrates the first $10-50 \mu \mathrm{m}$ of the sample surface (Demattê et al., 2016b). Vis-NIR spectra provide information inherent to the soil and are related primarily to its mineral constituents, organic compounds, and water content (Ben-Dor, 2002). In the spectrum, this information is represented by its intensity, shape, and absorption (spectral features) at specific wavelengths of electromagnetic radiation (Demattê, 2002).

Absorptions in the visible region occur due to the excitation of valence electrons present in some atoms and functional groups (Clark \& Roush, 1984). In soil organic molecules, these absorptions are restricted to certain functional groups (chromophores), which generate a rectilineal and concave shape across all spectra of the visible region. In inorganic species, such as iron oxides (e.g., hematite and goethite), absorption occurs due to 
charge transfer, usually between 500 and $650 \mathrm{~nm}$ wavelengths. In infrared, especially MIR, the wavelengths that present energy that is equivalent to the natural vibration frequencies of some molecules are absorbed and increase the intensity of these vibrations (Pavia et al., 2010). In the NIR, absorption occurs due to non-fundamental vibrations, which are overtones and combination tones of the fundamental vibrations. Non-fundamental vibrations are considered secondary vibrations, which have a lower intensity and are propagations of fundamental vibrations (Demattê et al., 2016b). Important absorption features in the soil spectra occur between 840 and $940 \mathrm{~nm}$, related to the presence of $\mathrm{Fe}$ oxides (e.g., hematite and goethite); between 1400 and $1900 \mathrm{~nm}$ due to the presence of water and hydroxyl molecules; between 2205 and $2225 \mathrm{~nm}$ related to the presence of kainite; and at $2265 \mathrm{~nm}$ in of the presence of gibbsite (Demattê, 2002). Other important information in the vis-NIR spectra is related to the scattering of energy throughout the spectra, which under stable conditions of acquisition geometry, sample roughness and source intensity is related to soil granulometry (Ben-Dor, 2002).

Worldwide, many attempts have been made to predict the physical and chemical attributes of soil using vis-NIR spectra. In general, calibrations of organic and total C, total $\mathrm{N}$, and clay content are more likely to succeed because clay minerals and $\mathrm{OM}$ are the spectrally active soil constituents, with well-known spectral features in the vis-NIR region (Ben-Dor, 2002). Available nutrients and other soil attributes (e.g., $\mathrm{CEC}, \mathrm{pH}$, and $\mathrm{V} \%$ ) do not present absorption features in this spectral region and, hence, their correlations with visNIR spectra are generally weak (Stenberg et al., 2010). However, there may be exceptions, as observed by Demattê et al. (2017) for available $\mathrm{Mg}$ and $\mathrm{K}$ in Brazilian tropical soils and by Mouazen and Kuang (2016) for available P in soils of temperate regions. These occasionally successful calibrations can be attributed to the covariance of soil attributes with some spectrally active constituents (Kuang et al., 2012). This behavior has generally been observed at the local level. In agricultural soils, this explanation is reasonable because nutrients are depleted with plant production, which is related to productivity. Depending on the degree to which the productivity is regulated by the clay and soil OM, the available nutrients will be associated with these variables and, consequently, with the vis-NIR spectrum (Stenberg et al., 2010). Detailed reviews of the fluctuations in the performance of vis-NIR sensors for the prediction of soil attributes have been shown in Stenberg et al. (2010) and Kuang et al. (2012).

In Brazilian tropical soils, most studies involve the application of vis-NIR sensors in a controlled environment (e.g., Demattê et al., 2002, 2003, 2004, 2015a) and embedded in remote sensing platforms (e.g., Nanni \& Demattê, 2006; Demattê et al., 2016a) for the digital survey of soils. Considering fertility attributes, predictive models with good results have been more frequent for soil texture, which have been obtained in a controlled environment (Demattê et al., 2015a; Lacerda et al., 2016; Cezar et al., 2019) and using orbital images (Demattê et al., 2016a). Laboratory analyses have also reported good prediction models for OM (Demattê et al., 2004; Cezar et al., 2019), CEC (Nanni \& Demattê, 2006), and available nutrients (Demattê et al., 2017). A promising approach using a visNIR sensor to characterize fertility classes in a Brazilian field of sugarcane production (185 ha) was presented by
Viscarra Rossel et al. (2010). The authors explored the multi-informational character of the vis-NIR spectra, associating it with the spatial information of the relief, using cluster analysis to define a fertility index for different zones. This approach allowed the grouping of three zones with contrasting fertility levels that should be managed using distinct fertilization strategies. Generating fertility indices is a strategy that allows for the grouping of key variables associated with soil fertility and is an interesting alternative to using soil sensor information in PA approaches (Iznaga et al., 2014; Askari et al., 2015). In addition, this approach is compatible with on-the-go surveys (Whetton et al., 2018), allowing spectral characterization of the field with more detailed spatial resolution.

Owing to the satisfactory performance of vis-NIR sensors in the laboratory, efforts have been made to develop equipment for field operations to perform on-the-go readings (Shibusawa et al., 1999; Christy, 2008). One of the main challenges of field applications using spectroanalytical techniques is to minimize the external effects (e.g., moisture, roughness, granulometry, and so on) that compromise part of the analytical performance of the sensors (Krug \& Rocha, 2017). DRS techniques in the laboratory require some sample preparation, such as drying and grinding, which ensures a better condition of the sample for spectral analysis (e.g., homogeneity, reduction of the effects promoted by roughness and moisture). The sample preparation procedure predominantly used for data acquisition with vis-NIR sensors involves soil drying and sieving $(<2 \mathrm{~mm})$ (Ben-Dor et al., 2015). Although direct sensing in the field does not require sample preparation, alternative methods can be adopted to minimize external effects, such as external parameter orthogonalization (Roger et al., 2003) and direct standardization (Wang et al., 1995). Some studies using vis-NIR spectroscopy directly in the field have achieved insensitive predictions of external effects using such methods (Wijewardane et al., 2016; Roudier et al., 2017). In Brazilian soils, Franceschini et al. (2013) was the pioneer in using on-the-go vis-NIR acquisitions. After using different methods to control for the external effects, the authors obtained prediction models with semi-quantitative potentials. They also highlighted the need to ensure stable geometry conditions between the sensor and soil during on-the-go surveys to obtain better performance.

Globally, few studies have reported the use of onthe-go vis-NIR techniques for fertility diagnosis and to delineate variable rate applications of fertilizers (e.g., Maleki et al., 2008; Mouazen \& Kuang, 2016). Groundbreaking research was presented by Mouazen and Kuang (2016), who presented an approach for the localized management of $\mathrm{P}$ in a 21-ha field in the United Kingdom, where they used a vis-NIR on-the-go spectrometer to build prescription maps of available $P$. In this study, the measurement of $\mathrm{P}$ was performed over 3 years $(2011,2012$, and 2013) following harvesting. After localized management, which was guided by the P prescription maps, an improvement in the spatial distribution of $\mathrm{P}$ was observed, reducing its coefficients of variation from $26 \%$ to $25 \%$ and, subsequently, to $16 \%$ in 2011,2012 , and 2013 , respectively. Despite the challenges of low-quality spectral data and inconsistent results for different areas, Mouazen and Kuang (2016) demonstrated the potential of the technique for a more assertive spatial diagnosis of fertility 
attributes in agricultural fields, achieving the benefits of localized management. Approaches utilizing multisensor systems and data fusion will open possibilities for new applications and improve the performance of current DRS techniques. Future studies in Brazilian tropical soils should be encouraged.

DRS sensors operating in the MIR region have similar characteristics to NIR sensors in relation to their design concept. However, traditionally, they present some particularities regarding their practicality of use and have greater difficulties in field application (Reeves III, 2010). MIR absorption features occur due to fundamental vibrations and, therefore, present higher intensity than those of NIR (Demattê et al., 2016b). MIR spectra have a greater number of features related to soil minerals and organic compounds compared to vis-NIR spectra, thus their calibrations are generally more robust (Viscarra Rossel et al., 2011). However, the sample preparation used traditionally for MIR analysis is more labor intensive than that for vis-NIR analysis because it involves the milling of material until a particle size between 80 and 100 $\mu \mathrm{m}$ (Janik et al., 1998).

Until recently, MIR sensors have not been applied directly in the field due to their high cost and fragility, as the risk in damaging the sensors does not compensate for the slight gain in performance compared to vis-NIR equipment (Viscarra Rossel et al., 2006). However, recent technological advances have allowed the development of portable prototypes, thus enabling field tests to be undertaken. Although MIR spectra are more sensitive to soil moisture and require sample preparation for particle size reduction (Reeves III, 2010), field tests using a MIR prototype have been promising (Dhawale et al., 2015; Ji et al., 2016). Thus, precedents have been set for this technique to be further exploited as a PSS technique. Dhawale et al. (2015) used a MIR sensor on soils simulating field conditions (with different moistures and particle sizes). They obtained predictions that were reasonable for soil texture and $\mathrm{MO}$, even with the occurrence of distortion in the spectra due to moisture. Ji et al. (2016) used a portable MIR sensor in the soil of two agricultural fields. Although the results varied for different areas, good prediction models $\left(\mathrm{R}^{2}>0.8\right)$ were observed for $\mathrm{MO}$, available $\mathrm{Ca}, \mathrm{CEC}$, and soil density. Only a few studies have been conducted in Brazilian tropical soils using MIR sensors to predict fertility attributes and no study has evaluated MIR sensors directly in the field. In the laboratory, evaluations by Demattê et al. (2015b) showed promising results for textural attributes (sand and clay), organic carbon, $\mathrm{CEC}, \mathrm{V} \%$ and acidity indicator attributes $\left(\mathrm{Al}^{3+}\right.$ and $\left.\mathrm{H}^{+}+\mathrm{Al}^{3+}\right)$. Additionally, in Brazilian soils, Madari et al. (2006) observed excellent results $\left(\mathrm{R}^{2}>0.90\right)$ for textural attributes and organic carbon.

\section{Electrochemical sensors}

The most common electrochemical sensors used for soil sensing are ion-selective electrodes (ISE) and the ionsensitive field-effect transistor (ISFET) (Gebbers \& Adamchuk, 2010). Both sensor systems respond selectively to a given ion $\left(e . g\right.$. $\mathrm{H}^{+}, \mathrm{K}^{+}, \mathrm{PO}_{4}{ }^{3-}$, and $\mathrm{NO}_{3}{ }^{-}$), following a logarithmic relationship between ion activity and the electrical potential, as described by the Nernst equation (Schirrmann et al., 2011). Electrochemical sensors require an ion recognition element (e.g., ion-selective membrane), which is integrated with a reference electrode that allows the measurement of the electrical potential difference between the soil and the standard solution, given in millivolts (mV) (Kim et al., 2009).

Electrochemical sensors can work in direct contact with a moist soil sample or inside a previously prepared solution (Sinfield et al., 2010). The measurements are relatively rapid and require a period to obtain signal stabilization, usually between 5 and 15 s (Adamchuk et al., 2005). Adamchuk et al. (1999) showed the applicability of electrochemical sensors directly on soil samples under field moisture conditions without preparing a soil solution, which has traditionally been used in laboratory analysis. The authors observed that humidity influenced the sensor reading, i.e., as the water content in the soil increased, the $\mathrm{mV}$ response decreased. However, among the common moisture ranges in mechanized field operations (15-25 $\left.\mathrm{g} \mathrm{g}^{-1}\right)$, this effect can be ignored because there is no significant difference in sensor response.

The good performance of electrochemical sensors applied directly on moist soil led to the creation of an automated soil collection system for on-the-go measurements (Adamchuk et al., 1999, 2005), which is now a commercial product ( $\mathrm{pH}$ Manager, Veris Technologies, Salina, USA). As it moves through the field, this system collects soil samples automatically at depths of approximately $10 \mathrm{~cm}$, using a rod driven by a hydraulic system. The collected samples are placed in direct contact with two ISE and, after signal stabilization, the $\mathrm{pH}$ value is recorded and associated with the positioning information collected by a global navigation satellite system receiver. After reading, the sampling rod returns to the soil for the collection of a new sample, with the tips of the electrodes being cleaned by two water jet nozzles. The system allows for the approximate collection of one sample every $15 \mathrm{~s}$. Similar to other on-the-go sensor systems, the spatial density of the analyzed samples depends on the speed of the operation and the distance between lines, which should be established based on the spatial variability range of the $\mathrm{pH}$ in the area to be mapped. At an average speed of $4 \mathrm{~ms}^{-1}$, with $20 \mathrm{~m}$ between the lines, a survey of approximately eight samples ha-1 can be obtained.

Using the on-the-go ISE system in German soils, Schirrmann et al. (2011) observed correlations ranging from 0.63 to 0.84 between the $\mathrm{pH}$ measured in the laboratory and the $\mathrm{pH}$ measured by electrochemical sensors. In the same study, the authors observed clear spatial relationships between the $\mathrm{pH}$ maps prescribed with the sensor system and those obtained using the traditional grid sampling method. The authors suggested that, although the ISE system directly measures the $\mathrm{pH}$ of the soil, specific calibrations for each field should be performed to reduce systematic errors. Schirrmann et al. (2011) emphasized that the only operational deficiency of the equipment occurs in fields that contain a lot of residual straw and weed roots, which can obstruct the sampler orifice. Similar accuracy results were obtained by Adamchuk et al. (2007) using the same sensor system in North American soils. Adamchuk et al. (2005) replaced the electrodes of the on-the-go system and studied the potential use of ISE for the measurement of $\mathrm{pH}$, available $\mathrm{K}$, nitrate, and $\mathrm{Na}$. The authors evaluated the accuracy of the readings of eight electrodes in the field. $\mathrm{R}^{2}$ values between the field and reference readings (laboratory) were around 0.93 and 0.96 for soil $\mathrm{pH}, 0.61$ and 0.62 for available $\mathrm{K}, 0.41$ and 0.51 for nitrate, and 0.11 for $\mathrm{Na}$. 
Sethuramasamyraja et al. (2008) used the same equipment with some adaptations and evaluated the accuracy of $\mathrm{pH}$, available $\mathrm{K}$, and nitrate measurements. The equipment was modified to collect samples and prepare them in an aqueous solution before reading by the ISE pairs. The $\mathrm{R}^{2}$ values between the field and laboratory data were 0.85 and 0.89 for soil $\mathrm{pH}, 0.50$ and 0.54 for available $\mathrm{K}$, and 0.14 and 0.32 for nitrate. Despite the reasonable results for available $\mathrm{K}$ and nitrate, the automated sample preparation before the ISE readings allowed a significant increase in its performance. This system represents an example of the automation of the sample preparation process, embedded in agricultural machinery, which is an engineering alternative for improving the performance of soil sensing techniques.

In Brazilian soils, electrochemical sensors for $\mathrm{pH}$ prediction were evaluated by Silva and Molin (2018) and Eitelwein et al. (2016), who both used the $\mathrm{pH}$ Manager equipment. These authors applied different methodologies to compare the ISE performance and the results found by both were divergent and ranged from good $\left(\mathrm{R}^{2}>0.8\right)$ to weak $\left(\mathrm{R}^{2}<0.1\right)$ predictions. However, when evaluated under controlled conditions (for example, when evaluating exactly the same portion of soil by ISE sensors and laboratory tests), the ISE showed good $\mathrm{pH}$ determinations. Further studies should be conducted in Brazilian tropical soils for the evaluation of different electrochemical sensors, as well as their synergy with other sensor systems.

\section{Gamma-ray spectroscopy}

The use of gamma-ray spectroscopy as a soil sensing technique in the context of PA is relatively recent (Viscarra Rossel et al., 2007). The spectral region of gamma radiation comprises very short wavelengths (high frequency). Passive gamma-ray spectrometers generally measure the intensity of radiation emitted between energies from 0 to $3 \mathrm{MeV}$ (Adamchuk \& Viscarra Rossel, 2010). Gamma-rays are emitted by the soil owing to the natural occurrence of radioisotopes, which naturally disintegrate and produce gamma radiation. The main radioisotopes present in the soils are $\mathrm{K}, \mathrm{U}$ (uranium), and Th (thorium). Each radioisotope emits a characteristic gamma radiation energy, which can be used for qualitative assessments. Under controlled attenuation conditions and with properly calibrated equipment, the emission intensity can be used to infer the concentrations of the isotopes (Wilford et al., 1997).

The spatial distribution and content of radioisotopes may be associated with traditional soil formation factors (e.g., parent material, pedogenetic processes, and so on), as well as anthropic actions (e.g., application and management of fertilizers) (Wetterlind et al., 2012). Thus, information on soil mineralogy, weathering, and chemical properties can be obtained by this form of sensing (Nawar et al., 2017). Soil isotope mapping can be accomplished by embedding gamma-ray sensors in agricultural equipment; commercial sensors for on-the-go mapping are already available (e.g., SoilOptix, Ontario, Canada). Approximately $95 \%$ of the gamma radiation measured in field surveys is emitted from the first $0.5 \mathrm{~m}$ of soil depth (Gregory \& Horwood, 1961). Different forms of attenuation, which can occur during the path taken from the radiation source (radioisotope) until the sensor detector, may interfere with the gamma-ray intensity measurements. In general, attenuations during field surveys occur due to variations in soil density and moisture, variations in ground cover (e.g., straw and vegetation), and atmospheric variations (e.g., temperature, pressure, and so on) (Taylor et al., 2002). According to Erdi-Krausz et al. (2003), attenuation can generate significant errors in field surveys. The authors also proposed that (i) increases in soil moisture by $10 \%$ may decrease the intensity of gamma-rays in the same proportion, (ii) $2 \mathrm{~cm}$ of plant cover can attenuate up to $35 \%$ of the gamma radiation, and (iii) different air density variations (generated by temperature and pressure variations) attenuate gamma-rays in the same proportion. Detailed information about the fundamental principles of gamma-ray spectroscopy, as well as a thorough discussion on the best practices for field surveys have been reviewed by Erdi-Krausz et al. (2003).

In the context of PA, some studies have indicated gamma-ray sensing as an alternative for predicting soil fertility attributes, such as clay content, $\mathrm{CEC}, \mathrm{pH}$, and available K (Viscarra Rossel et al., 2007; Castrignanò et al. 2012; Huang et al., 2014; Rodrigues et al., 2015). Viscarra Rossel et al. (2007) evaluated the spatial variability of radioisotopes in agricultural soils by performing on-the-go measurements with a portable gamma-ray spectrometer mounted on the front of a vehicle. The authors reported predictions with $\mathrm{R}^{2}$ higher than 0.70 for clay content, $\mathrm{pH}$, and $\mathrm{Fe}$ contents. Castrignanò et al. (2012) explored gammaray spectrum information by dividing it in different ways: (i) gamma-ray counts emitted by K; (ii) gamma-ray counts emitted by Th; (iii) gamma-ray counts emitted by U; and (iv) total gamma-ray counts. The authors observed satisfactory correlations between available $\mathrm{K}$ and gammaray counts emitted by $\mathrm{K}$, concluding that data obtained by this sensor have the potential to be used to improve $\mathrm{K}$ mappings accuracy.

Gamma-ray sensing has not yet been applied for the spatial evaluation of Brazilian tropical soils. However, Castilhos et al. (2015), using gamma-ray measurement in the laboratory on soil samples collected along a toposequence, classified variations in chemical properties among the different samples and made inferences about pedogenetic processes of the local landscape. Technological advances have compatibilized the use of passive gamma-ray sensors directly in the field, as well as successful applications of this technology for the characterization of agricultural soils from different regions (e.g., Castrignanò et al. 2012). Therefore, applications of this technology in Brazilian tropical soils should be encouraged.

\section{X-ray fluorescence (XRF) spectroscopy}

In recent years, there has been an increased interest in elemental analysis sensors, such as XRF and LIBS. These techniques are multi-elemental, allowing the measurement of the total content of a wide range of elements present in soil samples, such as $\mathrm{Si}, \mathrm{Fe}, \mathrm{Al}, \mathrm{K}, \mathrm{P}$, and $\mathrm{Ca}$. The techniques are compatible with the direct analysis of solids, and can obtain satisfactory analytical performances in soil samples with little or no preprocessing, and without generating chemical residues (Gredilla et al., 2016). Recent technological advances in optical and electronic components have allowed the development and miniaturization of these sensor systems, making both techniques more attractive for on-field analysis.

The XRF technique is based on the fluorescence induction of a sample utilizing its excitation with an incident X-ray source, followed by the measurement of 
specific photons that are emitted after this process (Kalnicky \& Singhvi, 2001). These photons also present energy in the X-ray region of the electromagnetic spectrum and this emitted energy is characteristic of each atom and, consequently, allows qualitative and quantitative analyses of most elements present in the samples (Jenkins, 1995). Heavy elements, that is, with higher atomic numbers (e.g., $\mathrm{Fe}, \mathrm{Co}$, and $\mathrm{Ni}$ ) are more accurately measured than elements of low atomic number (e.g., Si, Al, and $\mathrm{P}$ ) such that higher limits of detection (LOD) are observed for light elements. For example, P presents LOD of approximately $5000 \mathrm{mg}$ $\mathrm{kg}^{-1}$, whereas heavier elements, such as U, present a lower LOD of $\sim 5 \mathrm{mg} \mathrm{kg}^{-1}$ (Weindorf \& Chakraborty, 2016). In addition, elements with atomic numbers $<12$ cannot be detected by this technique (Jenkins, 1995). The XRF spectra acquisition time is a parameter that must be configured on these sensors. Generally, it is recommended that the readings last for approximately 30-90 s, with the longer the acquisition time, the greater the accuracy of the data (Weindorf \& Chakraborty, 2016).

Regarding sample preparation, procedures such as drying and comminution (reduction of particle size) allow the removal of moisture and promote homogenization of the sample, thus guaranteeing a gain in precision for XRF measurements (Krug \& Rocha, 2016). However, simplification or omission of sample preparation may still produce promising results. O'Rourke et al. (2016) used dry samples with a particle size $<2 \mathrm{~mm}$ (preparation procedure similar to that adopted in laboratory measurements with visNIR sensor) and obtained an $\mathrm{R}^{2}$ higher than 0.70 for the total content of $\mathrm{K}, \mathrm{Cr}, \mathrm{Cu}, \mathrm{Mn}$, and $\mathrm{Zn}$. Weindorf et al. (2012) used a portable XRF equipment to evaluate the chemical components in soil trenches, without any sample preparation. The authors reported that the technique allowed the observation of subtle chemical differences between the different horizons of a soil profile. Moreover, they obtained good prediction models $\left(\mathrm{R}^{2}>0.90\right)$ for organic C. An advantage of the field application of XRF when compared to DRS vis/NIR/MIR techniques is the lower influence of soil moisture on its spectra (Horta et al., 2015). Ge et al. (2005) presented a simple method for correcting the effect of moisture, stating that its application is necessary only in samples with a gravimetric moisture content above $20 \%$.

Although XRF equipment measures the total content of soil elements, these sensors have been suggested as an auxiliary technique for the evaluation of fertility attributes (O'Rourke et al. 2016; Nawar et al., 2019). In soils of temperate regions, good results have been reported for $\mathrm{pH}$ prediction (Sharma et al. 2014), CEC (Sharma et al. 2015), V \% (Rawal et al., 2019), soil texture (Zhu et al. 2011), and the total content of different elements (O'Rourke et al. 2016). In Brazilian tropical soils, satisfactory performances have been obtained for available $\mathrm{K}$ and $\mathrm{Ca}$ predictions (Tavares et al., 2019), organic C and MO (Morona et al., 2017), and textural attributes (Silva et al., 2018).

A comprehensive overview of the fundamentals and applications of the XRF technique using portable equipment for soil analysis, as well as discussions on quality control protocols, spectral interferences, equipment, and safety procedures, are shown in the United States Environmental Protection Agency's 6200 method (USEPA, 2007).

\section{Laser-induced breakdown spectroscopy (LIBS)}

LIBS, as well as XRF, is a spectroanalytical technique for elemental analysis. This technique uses a laser as an energy source to vaporize part of the surface of the material to be analyzed, causing a microsampling by ablation and subsequent excitation of atoms and ions. This excitation generates a microplasma that has its emission spectrum detected by a spectrometer, which is usually sensitive in the range between 200 and $900 \mathrm{~nm}$ (Harmon et al., 2013). The LIBS technique allows direct analysis of solids and is advantageous for its practicality, multielemental character, and micro-destructive technique (Yu et al., 2016). Moreover, it can be considered a complementary technique to XRF because it allows the quantification of elements with atomic numbers $<12$. The spectra acquisition by this technique is extremely fast, with the collection of 1-20 spectra per second (depending on laser frequency) (Krug \& Rocha, 2016).

For efficient quantitative applications of the LIBS technique, it is necessary to ensure that the laser promotes a congruent ablation in the analyzed samples, as well as an adequate plasma formation for the expulsion of the elements that compose the material (Senesi et al., 2009). This interaction between the laser and the sample, which involves ablation, vaporization, atomization, and excitation processes of the species in the plasma, must be reproducible (Gomes et al. 2011). Variations in the amount of the ablationated matter make it difficult to model the elements and replicate the generated models. Thus, the sample preparation before the application of the LIBS technique is of paramount importance and is one of the main challenges for applying the LIBS technique to soil samples under field conditions (Jantzi et al., 2016, 30). Thus, although technological advances have allowed the development of portable LIBS sensors (already marketed by some companies; e.g., Sciaps, Inc., Woburn, MA, USA), the application of such equipment for quantitative assessments in soil samples, directly in the field, still have challenges to be overcome.

In benchtop analysis, pellet preparation has been recommended for the evaluation of soil samples. Pellets are prepared by applying a high pressure $(\sim 784.53 \mathrm{MPa}$ or $8 \mathrm{t}$ $\mathrm{cm}^{-2}$ ) on dried and comminuted (with particle size usually $<$ $150 \mu \mathrm{m})$ soil samples. The comminution of the material is usually performed with a cryogenic grinding mill or ball mill. Sandy soils, with high silicate presence, do not form pellets only by pressing the comminuted material and require the addition of a binder material (e.g., cellulose, paraffin, and so on). When necessary, the binder material should not contain the elements of interest in the analysis, i.e., it must be inert. The pellet preparation, besides promoting material homogeneity, allows standardization of the density, porosity, and roughness of the sample surface (Krug \& Rocha, 2016). The smaller the particle size to be pressurized, the more resistant and cohesive will be the pellet, and therefore will present more uniform craters after laser ablation and better measurement accuracy (Carvalho et al., 2015).

In recent years, there has been growing interest in applying the LIBS technique for determining the fertility attributes of soil samples (Nicolodelli et al., 2019). Diaz et al. (2012) evaluated the application of LIBS in agricultural soils to determine the total content of some elements and 
obtained promising results $\left(\mathrm{R}^{2}>0.90\right)$ for the prediction of $\mathrm{Mg}, \mathrm{Ca}, \mathrm{Na}, \mathrm{P}$, and Fe. Recent studies have discussed the use of LIBS for the quantitative analysis of C (Senesi \& Senesi, 2016) and Ca (Rühlmann et al., 2018) total content. In Brazilian soils, different studies have shown the potential of this technique to predict clay, sand, and silt content (Villas-Boas et al., 2016); C (Nicolodelli et al., 2014) and $\mathrm{pH}$ values (Ferreira et al., 2015). In the latter study, the $\mathrm{pH}$ was predicted using the intensity of 32 different emission lines of $\mathrm{Al}, \mathrm{Ca}, \mathrm{H}$, and $\mathrm{O}$, in association with multivariate statistical techniques. Knadel et al. (2017) compared the performance between a LIBS sensor and a vis-NIR sensor to predict organic carbon and textural attributes of agricultural soils. The authors obtained good results with both techniques; however, the determinations performed with LIBS generally allowed for lower prediction errors. The authors emphasized that the sample preparation performed for the LIBS analyses (pellet preparation) is a key disadvantage of this technique compared to vis-NIR spectroscopy.

Some studies have suggested methodologies to reduce the physical effect of the matrix (Marangoni et al., 2016) and for correcting spectral interferences (Nicolodelli et al., 2014) to improve the performance of LIBS in soil analysis. Nicolodelli et al. (2019) reviewed advances over the last decade in the LIBS technique for soil analysis. They concluded that even though significant advances have been achieved in the detection limit of several elements, the reduction of matrix effects, the optimization of the signalto-noise ratio, and the application of modern chemometric methods, other aspects, such as utilizing the LIBS application directly in the field remain challenging and unexplored. The authors also commented that the great progress achieved in LIBS instrumentation, as well as the advances for its application in other areas (e.g., environmental and geological science), should encourage the agro-scientific community to develop more studies on LIBS sensors. This would accelerate the development of new approaches that can overcome the many disadvantages and limitations associated with the LIBS technique in the agricultural sector.

\section{Multisensor systems and data fusion}

Soils offer numerous scales of spatial and temporal variation that can be monitored using different sensor systems. Although studies using individual approaches of soil sensors have demonstrated the potential of different applications, no single sensor can completely characterize the complexity of the soil (Nawar et al., 2017). Each sensor presents an exclusive perspective on the possibilities of predicting physical and chemical attributes along the soil profile, which is a function of its design concept and operation type. Multisensor systems and data fusion techniques allow integrated information to be collected at different scales (both vertically and horizontally) and can be related to distinct soil properties, to deal with this challenge (Grunwald et al., 2015).

Data fusion is a multidisciplinary field based on different areas, including information technology, signal processing, statistical assessment and assumption, and artificial intelligence (Khaleghi et al., 2013). These approaches allow the integration of different forms of soil sensing, for example, multisensor systems acting on a benchtop, joint operation of different sensor systems directly in the field, integration between proximal and remote sensing techniques. Recently, the number of published studies on data fusion for the prediction of soil attributes has increased (Nawar et al., 2017). Increments in relation to individual sensor performances have been reported (e.g., O'Rourke et al., 2016), as well as the generation of new indices that allow subsidized localized management strategies (e.g., Benedetto et al., 2013; Mouazen et al., 2014). The ideal combination of sensors for predicting key fertility attributes, as well as robust and comprehensive strategies for data integration are still unknown. Studies in these areas should continue within the soil sensing community.

An example of information complementarity between different sensors is observed for elemental analysis techniques (e.g., LIBS and XRF) and DRS vis-NIR. The analysis of elements that are present in the soil performed using elemental analysis sensors enables the characterization of their inorganic constituents, while visNIR spectroscopy determines the mineralogical and organic components. The synergy between these techniques and the integrated use of these sensors has been attempted by recent studies (Horta et al., 2015; Wang et al., 2015; O'Rourke et al., 2016), which have shown better performance for predicting fertility attributes using joint predictions than individual ones.

The on-the-go use of multisensor platforms directly in the field has been attempted by some research groups (e.g., Lund et al., 2005; Castrignanò et al., 2012; Piikki et al., 2015). Lund et al. (2005), and subsequently Jonjak et al. (2010), reported the use of ECa and ISE sensors (sensitive to $\mathrm{H}^{+}$, for $\mathrm{pH}$ estimation) embedded in a mobile platform. This system, which is now a commercial product $(\mathrm{pH}$ Manager, Veris Technologies, Salina, USA), was developed for the prescription of lime applications at variable rates, as ECa helps to characterize the demands of lime for soils with similar acidity but different texture characteristics. Using this same platform, Schirrmann et al. (2012) adapted a vis-NIR spectrometer in its structure for on-the-go acquisition of spectral data simultaneously with $\mathrm{ECa}$ and $\mathrm{pH}$ data. When evaluating different agricultural fields, the authors reported that the different sensors showed a considerable difference in their ability to predict the key fertility attributes. Even without presenting satisfactory predictions for all attributes of interest, the authors concluded that the combined use of sensors allowed better adaptation to the field-to-field sensors performance variations. Moreover, data integration allowed the prediction of a wider range of attributes compared to the individual use of each sensor.

In Brazil, the pioneering work of Eitelwein (2017) evaluated the performance of a multisensor platform similar to that used by Schirrmann et al. (2012). The results obtained showed the possibility of joint and on-the-go operation of these sensors, thus allowing the verification of the spatial variability of some soil attributes. Despite this, some operational challenges must be overcome to improve the quality of data obtained using the different sensors. These challenges are (i) the use of weights in the structure in dry and compacted soils to avoid the depth oscillation of the ECa disks and spectrometer stem; (ii) soil adhesion in the spectrometer window under conditions of high humidity and clay content; and (iii) clogging the orifice of the $\mathrm{pH}$ sampler due to the presence of cultural residues in the soil. 
The author also reported that the spectral acquisitions while moving was the greatest challenge of the equipment, where the dynamics of the operation, heterogeneity of the microrelief, and soil moisture affected the data quality.

Castrignanò et al. (2012), working in a 80-ha agricultural field in Corrigin (Australia), integrated gammaray data, ECa, and relief information, together with geostatistical analyses to delineate areas of similar soil characteristics. The authors reported a successful case of using an integrated sensor in which the use of gamma-rays complemented the information from the ECa sensor. Some interesting aspects were observed in this research: (i) the potential use of gamma-rays to evaluate available K; (ii) similar spatial distribution between ECa and gamma-ray emission by $\mathrm{Th}, \mathrm{U}$, and the total gamma-ray counts, suggesting that they were influenced by the same soil property; and (iii) complementarity between ECa data and gamma-ray emission by $\mathrm{K}$.

To characterize different soil attributes at depth, different sensor systems have been proposed to be integrated into penetrometers. Yurui et al. (2008) reported the development of a multisensor equipment to measure soil physical properties, including moisture, mechanical resistance, and ECa. More recently, vis-NIR sensors have also been added, allowing an in-depth spectral characterization of the soil (Ackerson et al., 2017; Cho et al., 2017).

\section{FINAL CONSIDERATIONS}

The localized management of agricultural inputs, based on the mapping of the most diverse variables present in the field, provides agronomic and environmental benefits to agricultural production systems. Although it is currently the main PA approach in Brazil, the localized management of soil fertility is influenced by the spatial diagnosis of key soil attributes. The physical and chemical attributes related to soil fertility present different scales of spatial and temporal variations and their spatial distribution is usually characterized by short-range semivariograms. For reliable mapping of most of these attributes, a high density of spatial data $\left(>1\right.$ sample ha- $\left.{ }^{-1}\right)$ is required. Increasing the density of soil sampling points means additional costs associated with laboratory analysis and more effort for sample collection in the field. Alternatively, different sensor systems have been proposed to fill this information gap, allowing more practical, cheaper, and more sustainable approaches.

Technological advances in a wide range of sensors have allowed them to become smaller, more accurate, more efficient, and less expensive, which are better suited for direct field application. On-field application of this equipment, in a proximal way, that is, in contact or close to the soil surface, has led to the development of the PSS concept. Some sensors are compatible with PSS, allowing data acquisition in soils with minimum or no sample preparation; however, other technologies still need some sample preparation to maintain an acceptable analytical performance. In the present study, sensor systems compatible with the PSS concept were reviewed, as well as some technologies that require relatively simple sample preparations and that are compatible with user-friendly approaches. We also discussed the challenges of the spatiotemporal diagnosis of soil fertility attributes and the new perspective that soil sensing brings.
The effective use of soil sensors, aiming at more efficient management of fertility involves overcoming several multidisciplinary challenges. These challenges include: (i) understanding the design concept, potentialities, and limitations of different sensor systems; (ii) minimizing the loss of data quality when using PSS techniques; (iii) associating approaches of multivariate geostatistical with sensing techniques; (iv) adapting data fusion techniques with multisensor systems; and (v) developing general protocols to deal with field-by-field performance variations to facilitate recommendations of variable rate fertilization using sensors.

One of the main limitations of sensor-based soil management is that sensor data are usually related to more than one soil property. This leads to complex decision making and hinders the establishment of generalized protocols. However, at the local level, several scientific studies have overcome such difficulties, presenting successful applications of sensor systems for the localized management of soil fertility. There is an enormous demand for fertilizers and limestone in Brazilian tropical soils, as well as a global appeal for food security and a sustainable production environment. Hence, the development of effective techniques to use for soil sensing for environmental and yield benefits should be a necessity and local research should be encouraged.

Finally, we propose some topics that still have limited information in Brazilian tropical soils for future research: (i) develop practical applications for PSS techniques to associate the sensor systems output to the crop demands of fertilizers and limestone, allowing variable rate applications; (ii) explore the integration of PSS techniques with multivariate geostatistics approaches for targeted soil sampling to increase the accuracy of fertility attribute mapping; (iii) explore sensing techniques that have to date been little used in Brazilian soils (e.g., passive gamma-ray sensors), as well as synergism between different sensor systems already compatible with PSS; (iv) realize mediumand long-term assessments of environmental and economic gains arising from the use of PSS techniques for soil fertility management; (v) compare different sets of multisensor systems, as well as data fusion techniques for hybrid laboratories instrumentation; and (vi) use the different sensing techniques already available (e.g., PSS, optical canopy sensors, yield monitors) and seek innovative strategies for the local calibration of fertilizer prescription to overcome the limitations related to general recommendations of fertilizer applications.

\section{ACKNOWLEGMENTS}

The authors appreciate the financial support from the Research Foundation of São Paulo (FAPESP) through the doctoral fellowship of the second author (grant 2017/219690 ), as well as the partial financial support provided by the Coordination of Improvement of Higher Education Personnel (CAPES) and the National Council for Scientific and Technological Development (CNPQ). They also appreciate the Research and Projects Financier (FINEP) for supporting the PROSENSAP project. 


\section{REFERENCES}

Ackerson JP, Morgan CLS, Ge Y (2017) Penetrometermounted VisNIR spectroscopy: Application of EPO-PLS to in situ VisNIR spectra. Geoderma, 286: 131-138. DOI: https://doi.org/10.1016/j.geoderma.2016.10.018

Adamchuk VI, Morgan MT, Ess DR (1999) An automated sampling system for measuring soil $\mathrm{pH}$. Transactions of the ASAE, 42(4): 885. DOI: 10.13031/2013.13268.

Adamchuk VI, Hummel JW, Morgan MT, Upadhyaya SK (2004) On-the-go soil sensors for precision agriculture. Computers and electronics in agriculture, 44(1): 71-91. DOI: https://doi.org/10.1016/j.compag.2004.03.002

Adamchuk VI, Lund ED, Sethuramasamyraja B, Morgan MT, Dobermann A, Marx DB (2005) Direct measurement of soil chemical properties on-the-go using ion-selective electrodes. Computers and Electronics in Agriculture, 48(3): 272-294. DOI: https://doi.org/10.1016/j.compag.2005.05.001.

Adamchuk VI, Morgan MT, Brouder SM (2006) Development of an on-the-go soil pH mapping method: analysis of measurement variability. Applied Engineering Agriculture, 22(3): 335-344. DOI: 10.13031/2013.20450.

Adamchuk VI, Lund ED, Reed TM, Ferguson RB (2007) Evaluation of an on-the-go technology for soil $\mathrm{pH}$ mapping. Precision Agriculture, 8(3): 139-149. DOI: https://doi.org/10.1007/s11119-007-9034-0.

Adamchuk VI, Viscarra Rossel R (2010) Development of on-the-go proximal soil sensor systems. In Proximal soil sensing 15-28p. Springer, Dordrecht.

Askari MS, O'Rourke SM, Holden NM (2015) Evaluation of soil quality for agricultural production using visible-nearinfrared spectroscopy. Geoderma, 243: 80-91. DOI: https://doi.org/10.1016/j.geoderma.2014.12.012.

Ben-Dor E (2002) Quantitative remote sensing of soil properties. Advances in Agronomy, 75: 173-244. DOI: https://doi.org/10.1016/S0065-2113(02)75005-0.

Ben-Dor E, Banin, A (1995) Near-infrared analysis as a rapid method to simultaneously evaluate several soil properties. Soil Science Society of America Journal, 59(2): 364-372. DOI: 10.2136/sssaj1995.03615995005900020014x.

Ben-Dor E, Ong C, Lau IC (2015) Reflectance measurements of soils in the laboratory: Standards and protocols. Geoderma, 245: 112-124. DOI: https://doi.org/10.1016/j.geoderma.2015.01.002.

Benedetto D, Castrignanò A, Rinaldi M, Ruggieri S, Santoro F, Figorito B, Diacono M, Tamborrino R (2013) An approach for delineating homogeneous zones by using multi-sensor data. Geoderma, 199, 117-127. DOI: https://doi.org/10.1016/j.geoderma.2012.08.028.

Brevik EC, Fenton TE, Lazari A (2006) Soil electrical conductivity as a function of soil water content and implications for soil mapping. Precision Agric, 7:393-404. DOI: https://doi.org/10.1007/s11119-006-9021-X.

Brevik EC, Calzolari C, Miller BA, Pereira P, Kabala C, Baumgarten A, Jordán A (2016) Soil mapping, classification, and pedologic modeling: History and future directions. Geoderma, 264: 256-274. DOI: https://doi.org/10.1016/j.geoderma.2015.05.017.
Brock A, Brouder SM, Blumhoff G, Hofmann BS (2005) Defining yield-based management zones for corn-soybean rotations. Agronomy Journal, 97(4): 1115-1128. DOI: 10.2134/agronj2004.0220.

Brooks FA (1952) Atmospheric radiation and its reflection from the ground. Journal of Meteorology, 9(1): 41-52. DOI: https://doi.org/10.1175/1520-

0469(1952)009<0041:ARAIRF>2.0.CO;2.

Carvalho GGA, Santos Jr D, Gomes MS, Nunes LC, Guerra MBB, Krug FJ (2015) Influence of particle size distribution on the analysis of pellets of plant materials by laser-induced breakdown spectroscopy. Spectrochimica Acta Part B: Atomic Spectroscopy, 105, 130-135. DOI: https://doi.org/10.1016/j.sab.2014.09.001.

Castilhos ND, Melquiades FL, Thomaz EL, Bastos RO (2015) X-ray fluorescence and gamma-ray spectrometry combined with multivariate analysis for topographic studies in agricultural soil. Applied Radiation and Isotopes, 95: 6371. DOI: https://doi.org/10.1016/j.apradiso.2014.09.013.

Castrignanò A, Wong MTF, Stelluti M, Benedetto D, Sollitto D (2012) Use of EMI, gamma-ray emission and GPS height as multi-sensor data for soil characterisation. Geoderma, 175: 78-89. DOI:

https://doi.org/10.1016/j.geoderma.2012.01.013.

Cezar E, Nanni MR, Guerrero C, Silva Junior CA, Cruciol LGT, Chicati ML, Silva GFC (2019) Organic matter and sand estimates by spectroradiometry: Strategies for the development of models with applicability at a local scale. Geoderma, 340: 224-233. DOI:

https://doi.org/10.1016/j.geoderma.2019.01.021.

Cherubin MR, Santi AL, Eitelwein MT, Ros CO, Bisognin MB (2014a) Sampling grids used to characterise the spatial variability of $\mathrm{pH}, \mathrm{Ca}, \mathrm{Mg}$ and $\mathrm{V} \%$ in Oxisols. Revista Ciência Agronômica, 45(4): 659-672. DOI: http://dx.doi.org/10.1590/S1806-66902014000400004

Cherubin MR, Santi AL, Eitelwein MT, Menegol DR, Da Ros CO, Castro Pias OH, Berghetti J (2014b) Eficiência de malhas amostrais utilizadas na caracterização da variabilidade espacial de fósforo e potássio. Ciência Rural, 44(3): 425-432.

Cherubin MR, Santi AL, Eitelwein MT, Amado TJC, Simon DH, Damian JM (2015) Dimensão da malha amostral para caracterização da variabilidade espacial de fósforo e potássio em Latossolo Vermelho. Pesquisa Agropecuária Brasileira, 50(2): 168-177.

Cho Y, Sudduth KA, Drummond ST (2017) Profile soil property estimation using a vis-NIR-EC-force probe. Transactions of the ASABE, 60(3): 683-692. DOI: https://doi.org/10.13031/trans.12049.

Christy CD (2008) Real-time measurement of soil attributes using on-the-go near infrared reflectance spectroscopy. Computers and electronics in agriculture, 61(1): 10-19. DOI: https://doi.org/10.1016/j.compag.2007.02.010.

Clark RN, Roush TL (1984) Reflectance spectroscopy: Quantitative analysis techniques for remote sensing applications. Journal of Geophysical Research: Solid Earth, 89(B7): 6329-6340. DOI: https://doi.org/10.1029/JB089iB07p06329. 
Corwin DL, Lesch SM (2005) Apparent soil electrical conductivity measurements in agriculture. Computers and electronics in agriculture, 46(1-3): 11-43. DOI: https://doi.org/10.1016/j.compag.2004.10.005.

Crookston RK (2006) A top 10 list of developments and issues impacting crop management and ecology during the past 50 years. Crop science 46(5): 2253-2262. DOI: 0.2135/cropsci2005.11.0416gas.

De Jong E, Ballantyne AK, Cameron DR, Read DWL (1979) Measurement of Apparent Electrical Conductivity of Soils by an Electromagnetic Induction Probe to Aid Salinity Surveys 1. Soil Science Society of America Journal, 43(4): 810-812. DOI:

10.2136/sssaj1979.03615995004300040040x.

Demattê JAM (2002) Characterization and discrimination of soils by their reflected electromagnetic energy. Pesquisa Agropecuária Brasileira, 37(10): 1445-1458. DOI: http://dx.doi.org/10.1590/S0100-204X2002001000013

Demattê JAM, Pereira HS, Nanni MR, Cooper M, Fiorio PR (2003) Soil chemical alterations promoted by fertilizer application assessed by spectral reflectance. Soil Science, 168(10): 730-747. DOI:

10.1097/01.ss.0000095146.68539.09.

Demattê JA, Campos RC, Alves MC, Fiorio PR, Nanni MR (2004) Visible-NIR reflectance: a new approach on soil evaluation. Geoderma, 121(1-2): 95-112. DOI: https://doi.org/10.1016/j.geoderma.2003.09.012.

Demattê JAM, Alves MR, Gallo BC, Fongaro CT, Souza AB, Romero DJ, Sato MV (2015a) Hyperspectral remote sensing as an alternative to estimate soil attributes. Revista Ciencia Agronomica, 46(2): 223-232. DOI: http://dx.doi.org/10.5935/1806-6690.20150001.

Demattê JAM, Araújo SR, Fiorio PR, Fongaro CT, Nanni MR (2015b) Espectroscopia VIS-NIR-SWIR na avaliação de solos ao longo de uma topossequência em Piracicaba (SP). Revista Ciencia Agronomica, 46 (4): 679-688.

Demattê JAM, Alves MR, Terra FDS, Bosquilia RWD, Fongaro CT, Barros PPDS (2016a) Is it possible to classify topsoil texture using a sensor located $800 \mathrm{~km}$ away from the surface?. Revista Brasileira de Ciência do Solo, 40. DOI: http://dx.doi.org/10.1590/18069657rbcs20150335.

Demattê JAM, Morgan CLS, Chabrillat S, Rizzo R, Franceschini MHD, Terra F, Wetterlind J (2016b) Spectral sensing from ground to space in soil science: State of the art, applications, potential and perspectives. Land Resources Monitoring, Modeling, and Mapping with Remote Sensing. Thenkabail, PS, Ed, 661-732.

Demattê JA, Ramirez-Lopez L, Marques KPP, Rodella AA (2017) Chemometric soil analysis on the determination of specific bands for the detection of magnesium and potassium by spectroscopy. Geoderma, 288: 8-22. DOI: https://doi.org/10.1016/j.geoderma.2016.11.013.

Demattê JAM, Dotto AC, Bedin LG, Sayão VM, Souza AB (2019) Soil analytical quality control by traditional and spectroscopy techniques: Constructing the future of a hybrid laboratory for low environmental impact. Geoderma, 337: 111-121. DOI: https://doi.org/10.1016/j.geoderma.2018.09.010.
Dhawale NM, Adamchuk VI, Prasher SO, Viscarra Rossel RA, Ismail AA, Kaur J (2015) Proximal soil sensing of soil texture and organic matter with a prototype portable midinfrared spectrometer. European Journal of Soil Science, 66(4): 661-669. DOI: https://doi.org/10.1111/ejss.12265.

Diaz D, Hahn DW, Molina A (2012) Evaluation of laserinduced breakdown spectroscopy (LIBS) as a measurement technique for evaluation of total elemental concentration in soils. Applied Spectroscopy, 66(1): 99-106. DOI: https://doi.org/10.1366/11-06349.

Doolittle JA, Sudduth KA, Kitchen NR, Indorante SJ (1994) Estimating depths to claypans using electromagnetic induction methods. Journal of Soil and Water Conservation, 49(6): 572-575.

Dow AI, James DW (1973a) Intensive Soil Sampling: A Principle of Soil Fertility Management in Intensive Irrigation Agriculture. Washington Agricultural Experiment Station Bulletin 781. Washington State University, Pullman, WA.

Dow AI, James DW, Russell TS (1973b) Soil Variability in Central Washington and Sampling for Soil Fertility Tests. Washington Agricultural Experiment Station Bulletin 788, Washington State University, Pullman, WA.

Eitelwein MT, Trevisan RG, Colaço AF, Vargas MRI, Molin JP (2016) On-the-go measurements of $\mathrm{pH}$ in tropical soil, In Proceedings of the 13th International Conference on Precision Agriculture Monticello. In: International Society of Precision Agriculture.

Eitelwein MT (2017) Sensoriamento proximal de solo para a quantificação de atributos químicos e físicos. Dissertação de Doutorado, Universidade de São Paulo.

Erdi-Krausz G, Matolin M, Minty B, Nicolet JP, Reford WS, Schetselaar EM (2003) Guidelines for radioelement mapping using gamma-ray spectrometry data: also as open access ebook. International Atomic Energy Agency (IAEA).

FAO - Food and Agriculture Organization of the United Nations (2017) World Fertilizer Trends and Outlook to 2020. Food and Agriculture Organization of the United Nations (FAO), Rome, Italy.

Ferreira EC, Neto JAG, Milori DM, Ferreira EJ, Anzano JM (2015) Laser-induced breakdown spectroscopy: Extending its application to soil $\mathrm{pH}$ measurements. Spectrochimica Acta Part B: Atomic Spectroscopy, 110: 96-99. DOI: https://doi.org/10.1016/j.sab.2015.06.002

Foley Ja, Ramankutty N, Brauman Ka, Cassidy ES, Gerber JS, Johnston M, Mueller ND, O'Connell C, Ray DK, West PC, Balzer C, Bennett EM, Carpenter SR, Hill J, Monfreda C, Polasky S, Rockstrom J, Sheehan J, Siebert S, Tilman D, Zaks DPM (2011) Solutions for a cultivated planet. Nature 478(7369): 337-342. DOI: 10.1038/nature 10452

Fortes R, Millán S, Prieto MH, Campillo, C (2015) A methodology based on apparent electrical conductivity and guided soil samples to improve irrigation zoning. Precision agriculture, 16 (4): 441-454. DOI: https://doi.org/10.1007/s11119-015-9388-7. 
Franceschini MHD, Demattê JAM, Sato MV, Vicente LE, Grego CR (2013) Abordagens semiquantitativa e quantitativa na avaliação da textura do solo por espectroscopia de reflectância bidirecional no vis-NIR-SWIR. Pesquisa Agropecuária Brasileira, 48(12): 1569-1582,

Galuszka A, Migaszewski ZM, Namieśnik J (2015) Moving your laboratories to the field-Advantages and limitations of the use of field portable instruments in environmental sample analysis. Environmental research, 140: 593-603. DOI: https://doi.org/10.1016/j.envres.2015.05.017.

Ge L, Lai W, Lin Y (2005) Influence of and correction for moisture in rocks, soils and sediments on in situ XRF analysis. X-Ray Spectrometry: An International Journal, 34(1), 28-34. DOI: https://doi.org/10.1002/xrs.782

Gebbers R, Adamchuk VI (2010) Precision agriculture and food security. Science 327(5967): 828-831. DOI: 10.1126/science. 1183899 .

Godfray HCJ, Beddington JR, Crute IR, Haddad L, Lawrence D, Muir JF, Pretty J, Robinson S, Thomas, SM, Toulmin C (2010) Food Security: The Challenge of Feeding 9 Billion People. Science 327(5967): 812-818. DOI: 10.1126/science. 1185383 .

Gomes MS, Junior DS, Nunes LC, Carvalho GGA, Leme FO, Krug FJ (2011) Evaluation of grinding methods for pellets preparation aiming at the analysis of plant materials by laser induced breakdown spectrometry. Talanta, 85(4): 1744-1750. DOI: https://doi.org/10.1016/j.talanta.2011.06.069.

Gredilla A, Vallejuelo SFO, Elejoste N, Diego A, Madariaga JM (2016) Non-destructive Spectroscopy combined with chemometrics as a tool for Green Chemical Analysis of environmental samples: A review. TrAC Trends in Analytical Chemistry, 76: 30-39. DOI: https://doi.org/10.1016/j.trac.2015.11.011.

Gregory AF, Horwood JL (1961) A laboratory study of gamma-ray spectra at the surface of rocks (No. NP-10937; R-85). Geological Survey of Canada, Ottawa; Canada. Dept. of Mines and Technical Surveys. Mines Branch.

Gruijter JJ, McBratney AB, Taylor J (2010) Sampling for high-resolution soil mapping. In: Proximal soil sensing, 3$14 \mathrm{p}$. Springer, Dordrecht.

Grunwald S, Vasques GM, Rivero RG (2015) Fusion of soil and remote sensing data to model soil properties. In Advances in Agronomy 131: 1-109. Academic Press. DOI: https://doi.org/10.1016/bs.agron.2014.12.004.

Hammond MW (1993) Cost analysis of variable fertility management of phosphorus and potassium for potato production in central Washington. In: Proceedings of soil specific crop management. American Society of Agronomy, Crop Science Society of America, Soil Science Society of America.

Harmon RS, Russo RE, Hark RR (2013) Applications of laser-induced breakdown spectroscopy for geochemical and environmental analysis: A comprehensive review.

Spectrochimica Acta Part B: Atomic Spectroscopy, 87: 1126. DOI: https://doi.org/10.1016/j.sab.2013.05.017.

Hoefer G, Bachmann J, Hartge KH (2010) Can the EM38 probe detect spatial patterns of subsoil compaction?. In: Proximal Soil Sensing 265-273p. Springer, Dordrecht.
Horta A, Malone B, Stockmann U, Minasny B, Bishop TFA, McBratney AB, Pallasser R, Pozza L (2015) Potential of integrated field spectroscopy and spatial analysis for enhanced assessment of soil contamination: A prospective review. Geoderma, 241: 180-209. DOI:

https://doi.org/10.1016/j.geoderma.2014.11.024

Hossain MB, Lamb DW, Lockwood PV, Frazier P (2010) Field determination of soil moisture in the root zone of deep vertosoils using EM38 measurements: calibration and application issues. In: Proximal Soil Sensing 255-263p. Springer, Dordrecht.

Huang J, Lark RM, Robinson DA, Lebron I, Keith AM, Rawlins B, Tye A, Kuras O, Raines M, Triantafilis J (2014) Scope to predict soil properties at within-field scale from small samples using proximally sensed $\gamma$-ray spectrometer and EM induction data. Geoderma, 232: 69-80. DOI: https://doi.org/10.1016/j.geoderma.2014.04.031.

Hummel JW, Gaultney LD, Sudduth KA (1996) Soil property sensing for site-specific crop management. Computers and Electronics in Agriculture, 14(2-3): 121-136. DOI: https://doi.org/10.1016/0168-1699(95)00043-7.

Hyytiäinen K, Niemi JK, Koikkalainen K, Palosuo T, Salo T (2011) Adaptive optimization of crop production and nitrogen leaching abatement under yield uncertainty. Agricultural Systems, 104(8): 634-644. DOI: https://doi.org/10.1016/j.agsy.2011.06.006.

Iznaga AC, Orozco MR, Alcantara EA, Pairol MC, Sicilia YED, Baerdemaeker J, Saeys W (2014) Vis/NIR spectroscopic measurement of selected soil fertility parameters of Cuban agricultural Cambisols. Biosystems engineering, 125: 105-121. DOI: https://doi.org/10.1016/j.biosystemseng.2014.06.018.

Janik LJ, Merry RH, Skjemstad JO (1998) Can mid infrared diffuse reflectance analysis replace soil extractions? Australian Journal of Experimental Agriculture, 38(7): 681696. DOI: https://doi.org/10.1071/EA97144.

Jantzi SC, Motto-Ros V, Trichard F, Markushin Y, Melikechi N, Giacomo A (2016) Sample treatment and preparation for laser-induced breakdown spectroscopy. Spectrochimica Acta Part B: Atomic Spectroscopy, 115: 52-63. DOI: https://doi.org/10.1016/j.sab.2015.11.002.

Jenkins, R (1995) Quantitative X-ray spectrometry. CRC Press. DOI: https://doi.org/10.1201/9781482273380

Ji W, Adamchuk VI, Biswas A, Dhawale NM, Sudarsan B, Zhang Y, Viscarra Rossel RA, Shi Z (2016) Assessment of soil properties in situ using a prototype portable MIR spectrometer in two agricultural fields. Biosystems engineering, 152: 14-27. DOI:

https://doi.org/10.1016/j.biosystemseng.2016.06.005.

Jonjak AK, Adamchuk VI, Wortmann CS, Ferguson RB, Shapiro CA (2010) A comparison of conventional and sensor-based lime requirement maps. In: Proceedings of the Tenth International Conference on Precision Agriculture, Denver, Colorado, 18-21 July 2010, ed. R. Kholsa. Colorado State University, Fort Collins, Colorado, USA (CD publication, 15 pages). 
Kalnicky DJ, Singhvi R (2001) Field portable XRF analysis of environmental samples. Journal of hazardous materials, 83(1-2): 93-122. DOI: https://doi.org/10.1016/S03043894(00)00330-7.

Khaleghi B, Khamis A, Karray FO, Razavi SN (2013) Multisensor data fusion: A review of the state-of-the-art. Information fusion, 14(1): 28-44. DOI: https://doi.org/10.1016/j.inffus.2011.08.001.

Khosla R, Alley MM (1999) Soil-specific nitrogen management on Mid-atlantic coastal plain soils. Better Crop, 83(3): 6-7.

Kim HJ, Sudduth KA, Hummel JW (2009) Soil macronutrient sensing for precision agriculture. Journal of Environmental Monitoring, 11(10): 1810-1824. DOI: 10.1039/B906634A.

Knadel M, Gislum R, Hermansen C, Peng Y, Moldrup P, Jonge LW, Greve MH (2017) Comparing predictive ability of laser-induced breakdown spectroscopy to visible nearinfrared spectroscopy for soil property determination. Biosystems engineering, 156: 157-172. DOI: https://doi.org/10.1016/j.biosystemseng.2017.01.007.

Kodaira M, Shibusawa S (2013) Using a mobile real-time soil visible-near infrared sensor for high resolution soil property mapping. Geoderma, 199: 64-79. DOI: https://doi.org/10.1016/j.geoderma.2012.09.007.

Krug FJ, Rocha FRP (2016) Métodos de preparo de amostras para análise elementar. EditSBQ, Sociedade Brasileira de Química, São Paulo, 572p.

Kuang B, Mahmood HS, Quraishi MZ, Hoogmoed WB, Mouazen AM, Henten, EJV (2012) Sensing soil properties in the laboratory, in situ, and on-line: a review. In: Advances in Agronomy 114, 155-223p. Academic Press.

Kuang B, Mouazen AM (2011) Calibration of visible and near infrared spectroscopy for soil analysis at the field scale on three European farms. European Journal of Soil Science, 62(4): 629-636. DOI: https://doi.org/10.1111/j.1365-2389.2011.01358.x.

Leroux C, Jones H, Clenet A, Dreux B, Becu M, Tisseyre B (2018) A general method to filter out defective spatial observations from yield mapping datasets. Precision Agriculture, 19(5): 789-808. DOI:

https://doi.org/10.1007/s11119-017-9555-0.

Lund ED, Adamchuk VI, Collings KL, Drummond PE, \& Christy CD (2005) Development of soil $\mathrm{pH}$ and lime requirement maps using on-the-go soil sensors. In: Precision Agriculture: Papers from the Fifth European Conference on Precision Agriculture, Uppsala, Sweden, 9-12 June 2005, ed. J.Stafford, 457-464. Wageningen Academic Publishers, Wageningen, The Netherlands.

Machado PDA, Bernardi ADC, Valencia LIO, Molin JP, Gimenez LM, Silva CA, Meirelles MSP (2006)

Mapeamento da condutividade elétrica e relação com a argila de Latossolo sob plantio direto. Pesquisa Agropecuária Brasileira, 41(6): 1023-1031.
Madari BE, Reeves III JB, Machado PL, Guimarães CM, Torres E, McCarty GW (2006) Mid-and near-infrared spectroscopic assessment of soil compositional parameters and structural indices in two Ferralsols. Geoderma, 136(1-2): 245-259. DOI: https://doi.org/10.1016/j.geoderma.2006.03.026.

Maleki MR, Mouazen AM, Ketelaere B, Ramon H, Baerdemaeker J (2008) On-the-go variable-rate phosphorus fertilisation based on a visible and near-infrared soil sensor. Biosystems Engineering, 99(1): 35-46. DOI: https://doi.org/10.1016/j.biosystemseng.2007.09.007.

Marangoni, B. S., Silva, K. S., Nicolodelli, G., Senesi, G. S., Cabral, J. S., Villas-Boas, P. R., ... \& Milori, D. M. (2016). Phosphorus quantification in fertilizers using laser induced breakdown spectroscopy (LIBS): a methodology of analysis to correct physical matrix effects. Analytical Methods, 8(1), 78-82. DOI: 10.1039/C5AY01615K

Mc Bratney AB, Pringle MJ (1999) Estimating average and proportional variograms of soil properties and their potential use in precision agriculture. Precision Agriculture, 1(2): 125-152. DOI: https://doi.org/10.1023/A:1009995404447.

Mc Bratney AB, Santos MM, Minasny B (2003) On digital soil mapping. Geoderma, 117(1-2): 3-52. DOI: https://doi.org/10.1016/S0016-7061(03)00223-4.

Menegatti LAA, Molin JP (2004) Removal of errors in yield maps through raw data filtering. Revista Brasileira de Engenharia Agrícola e Ambiental, 8(1): 126-134. DOI: http://dx.doi.org/10.1590/S1415-43662004000100019

Molin JP, Gimenez LM, Pauletti V, Schmidhalter U, Hammer J (2005) Mensuração da condutividade elétrica do solo por indução e sua correlação com fatores de produção. Engenharia Agrícola, 25(2): 420-426.

Molin JP, Castro CND (2008) Establishing management zones using soil electrical conductivity and other soil properties by the fuzzy clustering technique. Scientia Agricola, 65(6): 567-573. DOI: http://dx.doi.org/10.1590/S0103-90162008000600001.

Molin JP, Rabello LM (2011) Estudos sobre a mensuração da condutividade elétrica do solo. Engenharia Agrícola, 31(1): 90-101.

Molin JP, Faulin GDC (2013) Spatial and temporal variability of soil electrical conductivity related to soil moisture. Scientia Agricola, 70(1): 01-05. DOI: http://dx.doi.org/10.1590/S0103-90162013000100001

Molin JP, Amaral LR, Colaço A (2015) Agricultura de precisão. São Paulo, Oficina de Textos. 238p.

Molin JP (2017) Agricultura de precisão: números do mercado brasileiro. Boletim Técnico 03. Disponível em: http://www,agriculturadeprecisao,org,br/upimg/publicacoes/ pub_-boletim-tecnico-03---agricultura-de-precisaonumeros-do-mercado-brasileiro-11-04-2017,pdf. Acessado 10 março, 2018.

Montanari R, Souza GSA, Pereira GT, Marques JJ, Siqueira DS, Siqueira GM (2012) The use of scaled semivariograms to plan soil sampling in sugarcane fields. Precision Agriculture, 13(5): 542-552. DOI:

https://doi.org/10.1007/s11119-012-9265-6. 
Monteiro FAS, Triantafilis J, Bruzgulis KE, Roe JAE (2010) Inversion of multiconfiguration electromagnetic (DUALEM -421) profiling data using a one dimensional laterally constrained algorithm. Vadose Zone Journal, 9: 117-125. DOI: $10.2136 /$ vzj2009.0088

Morona F, dos Santos FR, Brinatti AM, Melquiades FL (2017). Quick analysis of organic matter in soil by energydispersive X-ray fluorescence and multivariate analysis. Applied Radiation and Isotopes, 130, 13-20. DOI: https://doi.org/10.1016/j.apradiso.2017.09.008

Mouazen AM, Maleki MR, Baerdemaeker J, Ramon H (2007) On-line measurement of some selected soil properties using a vis-NIR sensor. Soil Tillage Research, 93(1): 13-27. DOI:

https://doi.org/10.1016/j.still.2006.03.009.

Mouazen AM, Alhwaimel SA, Kuang B, Waine T (2014) Multiple on-line soil sensors and data fusion approach for delineation of water holding capacity zones for site specific irrigation. Soil and Tillage Research, 143, 95-105. DOI: https://doi.org/10.1016/j.still.2014.06.003

Mouazen AM, Kuang B (2016) On-line visible and near infrared spectroscopy for in-field phosphorous management. Soil \& Tillage Research, 155: 471-477. DOI: https://doi.org/10.1016/j.still.2015.04.003.

Mulla D, Khosla R (2016) Historical Evolution and Recent Advances in Precision Farming. Soil-Specific Farming Precision Agriculture: 1-35.

Mulla DJ, Hammond, MW (1988) Mapping of soil test results from large irrigation circles. In: Proc. 39th Annual Far West Regional Fertilizer Conference, Bozeman, MT.

Mulla DJ (2013) Twenty-five years of remote sensing in precision agriculture: Key advances and remaining knowledge gaps. Biosystems Engineering, 114(4): 358-371. DOI: https://doi.org/10.1016/j.biosystemseng.2012.08.009.

Nanni MR, Demattê JAM (2006) Spectral reflectance methodology in comparison to traditional soil analysis. Soil Science Society of America Journal, 70(2): 393-407. DOI: 10.2136/sssaj2003.0285.

Nanni MR, Povh FP, Demattê JAM, Oliveira RBD, Chicati ML, Cezar E (2011) Optimum size in grid soil sampling for variable-rate application in site-specific management.

Scientia Agricola, 68(3): 386-392. DOI: http://dx.doi.org/10.1590/S0103-90162011000300017.

Nawar S, Corstanje R, Halcro G, Mulla D, Mouazen AM (2017) Delineation of soil management zones for variablerate fertilization: A review. In: Advances in agronomy 143: 175-245. Academic Press. DOI:

https://doi.org/10.1016/bs.agron.2017.01.003.

Nawar S, Delbecque N, Declercq Y, Smedt P, Finke P, Verdoodt A, Meirvenne MV, Mouazen AM (2019) Can spectral analyses improve measurement of key soil fertility parameters with X-ray fluorescence spectrometry?. Geoderma, 350: 29-39. DOI: https://doi.org/10.1016/j.geoderma.2019.05.002.
Nicolodelli G, Marangoni BS, Cabral JS, Villas-Boas PR, Senesi GS, dos Santos CH, ... \& Milori D M (2014). Quantification of total carbon in soil using laser-induced breakdown spectroscopy: a method to correct interference lines. Applied optics, 53(10): 2170-2176. DOI: https://doi.org/10.1364/AO.53.002170

Nicolodelli G, Cabral J, Menegatti CR, Marangoni B, Senesi GS (2019) Recent advances and future trends in LIBS applications to agricultural materials and their food derivatives: an overview of developments in the last decade (2010-2019). Part I. Soils and fertilizers. TrAC Trends in Analytical Chemistry. DOI: https://doi.org/10.1016/j.trac.2019.03.032

Officer SJ, Kravchenko A, Bollero GA, Sudduth KA, Kitchen NR, Wiebold WJ, Palm HL, Bullock DG (2004) Relationships between soil bulk electrical conductivity and the principal component analysis of topography and soil fertility values. Plant Soil, 258: 269-280. DOI: https://doi.org/10.1023/B:PLSO.0000016557.94937.ed.

O'Rourke SM, Stockmann, U, Holden NM, McBratney, AB, \& Minasny B, (2016) An assessment of model averaging to improve predictive power of portable vis-NIR and XRF for the determination of agronomic soil properties. Geoderma, 279: 31-44. DOI: https://doi.org/10.1016/j.geoderma.2016.05.005

Pan L, Adamchuk V, Prasher S, Gebbers R, Taylor R, Dabas M (2014) Vertical soil profiling using a galvanic contact resistivity scanning approach. Sensors, 14(7): 13243-13255. DOI: https://doi.org/10.3390/s140713243.

Pandey S, Bhatta NP, Paudel P, Pariyar R, Maskey KH, Khadka J, Thapa TB, Rijal B, Panday D (2017) Improving fertilizer recommendations for Nepalese farmers with the help of soil-testing mobile van. Journal of Crop Improvement, 32(1): 19-32. DOI:

https://doi.org/10.1080/15427528.2017.1387837.

Pavia DL, Lampman GM, Kriz GS, Vyvyan JR (2010) Introdução à espectroscopia. Cengage Learning.

Piikki K, Wetterlind J, Söderström M, Stenberg B (2015) Three-dimensional digital soil mapping of agricultural fields by integration of multiple proximal sensor data obtained from different sensing methods. Precision agriculture, 16(1): 29-45. DOI: https://doi.org/10.1007/s11119-014-9381-6

Prado H (2005) Ambientes de produção de cana-de-açúcar na região Centro-Sul do Brasil. Informações Agronômicas,110: 12- 17. Encarte Técnico.

Rawal A, Chakraborty S, Li B, Lewis K, Godoy M, Paulette L, Weindorf DC (2019) Determination of base saturation percentage in agricultural soils via portable X-ray fluorescence spectrometer. Geoderma, 338: 375-382. DOI: https://doi.org/10.1016/j.geoderma.2018.12.032.

Reeves III JB (2010) Near-versus mid-infrared diffuse reflectance spectroscopy for soil analysis emphasizing carbon and laboratory versus on-site analysis: where are we and what needs to be done?. Geoderma, 158(1-2): 3-14. DOI: https://doi.org/10.1016/j.geoderma.2009.04.005. 
Resende AV, Coelho A (2017) Amostragem para mapeamento e manejo da fertilidade do solo na abordagem de agricultura de precisão. International Plant Nutrition Institute (IPNI): Informações Agronômicas, 156: 1-8. Disponível em: http://www.ipni.net/publication/ia-brasil.nsf

Rodrigues Jr FA, Bramley RGV, Gobbett DL (2015)

Proximal soil sensing for precision agriculture:

Simultaneous use of electromagnetic induction and gamma radiometrics in contrasting soils. Geoderma, 243: 183-195. DOI: https://doi.org/10.1016/j.geoderma.2015.01.004.

Roger JM, Chauchard F, Bellon-Maurel V (2003) EPO-PLS external parameter orthogonalisation of PLS application to temperature-independent measurement of sugar content of intact fruits. Chemometrics and Intelligent Laboratory Systems, 66(2): 191-204. DOI:

https://doi.org/10.1016/S0169-7439(03)00051-0.

Roudier P, Hedley CB, Lobsey CR, Rossel RV, Leroux C (2017) Evaluation of two methods to eliminate the effect of water from soil vis-NIR spectra for predictions of organic carbon. Geoderma, 296: 98-107. DOI:

https://doi.org/10.1016/j.geoderma.2017.02.014.

Rühlmann M, Büchele D, Ostermann M, Bald I, Schmid T (2018) Challenges in the quantification of nutrients in soils using laser-induced breakdown spectroscopy-A case study with calcium. Spectrochimica Acta Part B: Atomic

Spectroscopy, 146: 115-121. DOI:

https://doi.org/10.1016/j.sab.2018.05.003.

Sanches GM, Magalhães PS, Remacre AZ, Franco HC (2018) Potential of apparent soil electrical conductivity to describe the soil $\mathrm{pH}$ and improve lime application in a clayey soil. Soil and Tillage Research, 175: 217-225. DOI: https://doi.org/10.1016/j.still.2017.09.010.

Sanches GM, Paula MTND, Magalhães PSG, Duft DG, Vitti AC, Kolln OT, Borges BMMN, Franco HCJ (2019) Precision production environments for sugarcane fields. Scientia Agricola, 76(1): 10-17. DOI:

http://dx.doi.org/10.1590/1678-992x-2017-0128.

Schirrmann M, Domsch H (2011) Sampling procedure simulating on-the-go sensing for soil nutrients. Journal of Plant Nutrition and Soil Science, 174(2): 333-343. DOI: https://doi.org/10.1002/jpln.200900367.

Schirrmann M, Gebbers R, Kramer E, Seidel J (2011) Soil pH mapping with an on-the-go sensor. Sensors, 11(1): 573598. DOI: https://doi.org/10.3390/s110100573.

Schirrmann M, Gebbers R, Kramer E. (2012) Field scale mapping of soil fertility parameters by combination of proximal soil sensors. In: Infomation Technology, Automation and Precision Farming. International Conference of Agricultural Engineering-CIGR-AgEng 2012: Agriculture and Engineering for a Healthier Life, Valencia, Spain, 8-12 July 2012. CIGR-EurAgEng. Disponível em:

https://www.cabdirect.org/cabdirect/abstract/20133223206.

Senesi GS, Dell'Aglio M, Gaudiuso R, Giacomo A, Zaccone C, Pascale O, Miano TM, Capitelli M (2009) Heavy metal concentrations in soils as determined by laserinduced breakdown spectroscopy (LIBS), with special emphasis on chromium. Environmental research, 109(4): 413-420. DOI: https://doi.org/10.1016/j.envres.2009.02.005.
Senesi GS, Senesi N (2016) Laser-induced breakdown spectroscopy (LIBS) to measure quantitatively soil carbon with emphasis on soil organic carbon. A review. Analytica chimica acta, 938: 7-17. DOI:

https://doi.org/10.1016/j.aca.2016.07.039.

Serrano JM, Shahidian S, Silva, JM (2017) Spatial variability and temporal stability of apparent soil electrical conductivity in a Mediterranean pasture. Precision agriculture, 18(2): 245-263. DOI: https://doi.org/10.1007/s11119-016-9460-y.

Sethuramasamyraja B, Adamchuk VI, Dobermann A, Marx DB, Jones DD, Meyer GE (2008) Agitated soil measurement method for integrated on-the-go mapping of soil $\mathrm{pH}$, potassium and nitrate contents. Computers and electronics in agriculture, 60(2): 212-225. DOI: https://doi.org/10.1016/j.compag.2007.08.003.

Sharma A, Weindorf DC, Man T, Aldabaa AAA, Chakraborty S (2014) Characterizing soils via portable Xray fluorescence spectrometer: 3 , Soil reaction $(\mathrm{pH})$. Geoderma, 232: 141-147. DOI: https://doi.org/10.1016/j.geoderma.2014.10.001.

Sharma A, Weindorf DC, Wang D, Chakraborty S (2015) Characterizing soils via portable X-ray fluorescence spectrometer: 4, Cation exchange capacity (CEC). Geoderma, 239: 130-134. DOI: https://doi.org/10.1016/j.geoderma.2014.10.001.

Shibusawa S, Li MZ, Sakai K, Saao A, Sato H, Hirako S, Otomo A (1999). Spectrophotometer for real-time underground soil sensing. ASAE Paper No. 993030, ASAE, St. Joseph, Mich.

Silva FCDS, Molin JP (2018) On-the-go tropical soil sensing for $\mathrm{pH}$ determination using ion-selective electrodes. Pesquisa Agropecuária Brasileira, 53(11): 11891202. DOI: tp://dx.doi.org/10.1590/s0100204x2018001100001.

Silva SHG, Hartemink AE, Teixeira AFS, Inda AV, Guilherme LRG, Curi N (2018) Soil weathering analysis using a portable X-ray fluorescence (PXRF) spectrometer in an Inceptisol from the Brazilian Cerrado. Applied Clay Science, 162: 27-37. DOI: https://doi.org/10.1016/j.clay.2018.05.028.

Sinfield JV, Fagerman D, Colic O (2010) Evaluation of sensing technologies for on-the-go detection of macronutrients in cultivated soils. Computers and Electronics in Agriculture, 70(1): 1-18. DOI:

https://doi.org/10.1016/j.compag.2009.09.017.

Steinberger G, Rothmund M, Auernhammer H (2009) Mobile farm equipment as a data source in an agricultural service architecture. Computers and electronics in agriculture, 65(2): 238-246. DOI:

https://doi.org/10.1016/j.compag.2008.10.005.

Stenberg B, Viscarra Rossel RA, Mouazen AM, Wetterlind J (2010) Visible and near-infrared spectroscopy in soil science. Advances in Agronomy, 107: 163-215. DOI: https://doi.org/10.1016/S0065-2113(10)07005-7.

Sudduth KA, Hummel JW (1991) Evaluation of reflectance methods for soil organic matter sensing. Transactions of the ASAE, 34(4): 1900-1909. DOI: 10.13031/2013.31816. 
Sudduth KA, Drummond ST, Kitchen NR (2001) Accuracy issues in electromagnetic induction sensing of soil electrical conductivity for precision agriculture. Computers and electronics in agriculture, 31(3): 239-264. DOI: https://doi.org/10.1016/S0168-1699(00)00185-X.

Sudduth KA, Kitchen NR, Wiebold WJ, Batchelor WD, Bollero GA, Bullock DG, Clay DE, Palm HL, Pierce, FJ, Schuler RT, Thelen KD (2005) Relating apparent electrical conductivity to soil properties across the north- central USA. Computers and Electronics in Agriculture, 46(1-3): 263-283. DOI: https://doi.org/10.1016/j.compag.2004.11.010.

Sudduth KA, Myers DB, Kitchen NR, Drummond ST (2013) Modeling soil electrical conductivity-depth relationships with data from proximal and penetrating $\mathrm{ECa}$ sensors. Geoderma, 199: 12-21. DOI:

https://doi.org/10.1016/j.geoderma.2012.10.006.

Tavares TR, Nunes LC, Carvalho HWP, Alves EEN, Krug FJ, Molin JP (2019) Sample preparation for assessing the potential use of XRF on soil fertility analysis. In Proceedings of the 13th International Conference on Precision Agriculture (online), Columbia, MO: Global Workshop on Proximal Soil Sensing. Disponível em: https://www.pss2019.org/.

Taylor MJ, Smettem K, Pracilio G, Verboom W (2002) Relationships between soil properties and high-resolution radiometrics, central eastern Wheatbelt, Western Australia. Exploration geophysics, 33(2): 95-102. DOI: https://doi.org/10.1071/EG02095.

USEPA - United States Environmental Protection Agency (2007) Method 6200: Field portable X-ray fluorescence spectrometry for the determination of elemental concentrations in soil and sediment. Disponível em: http://www.epa.gov/osw/hazard/ testmethods/sw846/pdfs/6200.pdf. Acessado em: 11 de julho de 2019.

Veseth R (1986) Managing variable soils. STEEP Extension Farming Update, Fall issue, 29-33p.

Villas-Boas PR, Romano RA, Franco MAM Ferreira EC, Ferreira EJ, Crestana S, Milori DMBP (2016) Laser-induced breakdown spectroscopy to determine soil texture: A fast analytical technique. Geoderma, 263: 195-202. DOI: http://dx.doi.org/10.1016/j.geoderma.2015.09.018.

Viscarra Rossel R, Walvoort DJJ, McBratney AB, Janik LJ, Skjemstad JO (2006) Visible, near infrared, mid infrared or combined diffuse reflectance spectroscopy for simultaneous assessment of various soil properties. Geoderma, 131(1-2): 59-75. DOI: https://doi.org/10.1016/j.geoderma.2005.03.007.

Viscarra Rossel RA, Taylor HJ, McBratney, AB (2007) Multivariate calibration of hyperspectral $\gamma$-ray energy spectral for proximal soil sensing. European Journal of Soil Science, 58(1): 343-353.

DOI: https://doi.org/10.1111/j.1365-2389.2006.00859.x.
Viscarra Rossel RA, Rizzo R, Demattê JAM, Behrens T (2010) Spatial modeling of a soil fertility index using visible-near-infrared spectra and terrain attributes. Soil Science Society of America Journal, 74(4): 1293-1300. DOI: 10.2136/sssaj2009.0130.

Viscarra Rossel RA, Adamchuk VI, Sudduth KA, McKenzie NJ, Lobsey C (2011) Proximal soil sensing: an effective approach for soil measurements in space and time. In: Advances in agronomy 113, p 243-291. Academic Press.

Viscarra Rossel RA, Bouma J (2016) Soil sensing: A new paradigm for agriculture. Agricultural Systems, 148: 71-74. DOI: https://doi.org/10.1016/j.agsy.2016.07.001

Viscarra Rossel RA, Lobsey C (2016) Scoping review of proximal soil sensors for grain growing. CSIRO, Australia.

Vrindts E, Mouazen AM, Reyniers M, Maertens K, Maleki MR, Ramon H, Baerdemaeker J (2005) Management zones based on correlation between soil compaction, yield and crop data. Biosyst. Eng., 92: 419-428. DOI:

https://doi.org/10.1016/j.biosystemseng.2005.08.010.

Wang D, Chakraborty S, Weindorf DC, Li B, Sharma A, Paul S, Ali M N (2015) Synthesized use of VisNIR DRS and PXRF for soil characterization: Total carbon and total nitrogen. Geoderma, 243: 157-167. DOI: https://doi.org/10.1016/j.geoderma.2014.12.011

Wang Z, Dean T, Kowalski BR (1995) Additive background correction in multivariate instrument standardization. Analytical Chemistry, 67(14): 2379-2385. DOI: https://doi.org/10.1021/ac00110a009.

Webster R, Mc Bratney AB (1987) Mapping soil fertility at Broom's Barn by simple kriging. Journal of the Science of Food and Agriculture, 38(2): 97-115. DOI: https://doi.org/10.1002/jsfa.2740380203.

Weindorf DC, Zhu Y, Mc Daniel P, Valerio M, Lynn L, Michaelson G, Clark M, Ping, C. L (2012) Characterizing soils via portable $\mathrm{x}$-ray fluorescence spectrometer: 2 . Spodic and Albic horizons. Geoderma, 189: 268-277. DOI: https://doi.org/10.1016/j.geoderma.2012.06.034

Weindorf DC, Chakraborty S (2016) Portable X-ray Fluorescence Spectrometry Analysis of Soils. In: Methods of Soil Analysis, SSSA Book Ser. 5. SSSA, Madison, WI. DOI:10.2136/methods-soil.2015.0033.

Weltzien C (2016) Digital Agriculture or Why Agriculture 4.0 Still Offers Only Modest Returns. Landtechnik, 71(2): 66-68. DOI: 10.15150/lt.2015.3123

Wetterlind J, Stenberg B, Söderström M (2010) Increased sample point density in farm soil mapping by local calibration of visible and near infrared prediction models. Geoderma, 156(3-4): 152-160. DOI:

https://doi.org/10.1016/j.geoderma.2010.02.012.

Wetterlind J, Tourlière B, Martelet G, Deparis J, Saby NP, Forges ACR, Arrouays D (2012) Are there any effects of the agricultural use of chemical fertiliser on elements detected by airborne gamma-spectrometric surveys?. Geoderma, 173: 34-41. DOI: https://doi.org/10.1016/j.geoderma.2012.01.011. 
Whetton R, Zhao Y, Mouazen AM (2018) Quantifying individual and collective influences of soil properties on crop yield. Soil Research, 56(1): 19-27. DOI: https://doi.org/10.1071/SR16264.

Wijewardane NK, Ge Y, Morgan CL (2016) Moisture insensitive prediction of soil properties from VNIR reflectance spectra based on external parameter orthogonalization. Geoderma, 267: 92-101. DOI: https://doi.org/10.1016/j.geoderma.2015.12.014.

Wilford JR, Bierwirth PE, Craig MA (1997) Application of airborne gamma-ray spectrometry in soil/regolith mapping and applied geomorphology. AGSO Journal of Australian Geology and Geophysics, 17(2): 201-216.

Wollenhaupt NC, Wolkowski RP, Clayton MK (1994) Mapping soil test phosphorus and potassium for variablerate fertilizer application. Journal of Production Agriculture, 7(4): 441-448. DOI: 10.2134/jpa1994.0441.
Yu KQ, Zhao YR, Liu F, He Y (2016) Laser-induced breakdown spectroscopy coupled with multivariate chemometrics for variety discrimination of soil. Scientific reports, 6: 27574. DOI: https://doi.org/10.1038/srep27574.

Yurui S, Lammers PS, Daokun M, Jianhui L, Qingmeng Z. (2008) Determining soil physical properties by multi-sensor technique. Sensors and Actuators A: Physical, 147(1), 352357. DOI: https://doi.org/10.1016/j.sna.2008.05.014

Zare E, Huang J, Santos FA, Triantafilis J (2015) Mapping salinity in three dimensions using a DUALEM-421 and electromagnetic inversion software. Soil Science Society of America Journal, 79(6): 1729-1740.

Zhu Y, Weindorf DC, Zhang W (2011) Characterizing soils using a portable X-ray fluorescence spectrometer: 1. Soil texture. Geoderma, 167: 167-177. DOI:

https://doi.org/10.1016/j.geoderma.2011.08.010. 